Allen et al. 1

\title{
Psychological stress disrupts intestinal epithelial cell function and mucosal integrity through microbe and host-directed processes
}

Jacob M. Allen ${ }^{1,2^{*}}$, Amy R. Mackos ${ }^{2,3}$ Robert M. Jaggers ${ }^{2}$, Patricia C. Brewster ${ }^{1}$, Mikaela Webb ${ }^{1}$, Chia-Hao Lin ${ }^{1}$, Chris Ladaika ${ }^{2}$, Ronald Davies ${ }^{2}$, Peter White ${ }^{4}$, Brett R. Loman ${ }^{2,5}$ and Michael T. Bailey $2,6,7^{*}$

1. Department of Kinesiology and Community Health, University of Illinois at UrbanaChampaign, 906 S. Goodwin Ave, Urbana, IL $61820^{2}$. Center for Microbial Pathogenesis, Abigail Wexner Research Institute at Nationwide Children's Hospital, 700 Children's Drive, Columbus, OH 43250. ${ }^{3}$. College of Nursing, The Ohio State University, 1585 Neil Ave, Columbus, $\mathrm{OH}$ 43210. ${ }^{4}$. Steve and Cindy Rasmussen Institute for Genomic Medicine, Nationwide Children's Hospital, 575 Children's Crossroad, Columbus, OH 432155. Department of Animal Sciences, University of Illinois at Urbana-Champaign, 1207 W Gregory Drive Urbana, IL 61801. ${ }^{6}$. Department of Pediatrics, The Ohio State University College of Medicine, $370 \mathrm{~W} 9^{\text {th }}$ Ave, Columbus, OH 43250. 7. Oral and GI Microbiology Research Affinity Group, Abigail Wexner Research Institute at Nationwide Children's Hospital, Columbus, $\mathrm{OH} 43250$.

\section{Address Correspondence to:}

*Co-corresponding authors

*Jacob M. Allen, $\mathrm{PhD}$.

Department of Kinesiology and Community Health

Division of Nutritional Sciences

University of Illinois at Urbana-Champaign

41 Urbana, IL 61801

* Michael T. Bailey, PhD.

Center for Microbial Pathogenesis Abigail Wexner Research Institute Nationwide Children's Hospital 906 S Goodwin AVE, M/C 052 
Allen et al. 2

\section{Abstract}

47 Psychological stress alters the gut microbiota and predisposes individuals to increased risk for enteric infections and chronic bowel conditions. Intestinal epithelial cells (IECs) are responsible

49 for maintaining homeostatic interactions between the gut microbiota and its host. In this study,

50 we hypothesized that disruption to colonic IECs is a key factor underlying stress-induced

51 disturbances to intestinal homeostasis. Conventionally raised (CONV-R) and germ-free (GF)

52 mice were exposed to a social disruption stressor (Str) to ascertain how stress modifies colonic

53 IECs, the mucosal layer, and the gut microbiota. RNA sequencing of IECs isolated from CONV-

$54 \mathrm{R}$ mice revealed a robust pro-inflammatory (Saa1, Il18), pro-oxidative (Duox2, Nos2), and

55 antimicrobial $(\operatorname{Reg} 3 \mathrm{~b} / \mathrm{g})$ transcriptional profile as a result of Str. This response occurred

56 concomitant to mucus layer thinning and signs of microbial translocation. In contrast to their

57 CONV-R counterparts, IECs from GF mice or mice treated with broad spectrum antibiotics

58 exhibited no detectable transcriptional changes in response to Str. Nevertheless, IECs from Str-

59 exposed GF mice exhibited an altered response to ex vivo bacterial challenge (increased dual

60 Oxidase-2 [Duox2] and nitric oxide synthase-2 (Nos2)), indicating that STR primes host IEC

61 pro-oxidative responses. In CONV-R mice stress-induced increases in colonic Duox2 and Nos 2

62 (ROS generating enzymes) strongly paralleled changes to microbiome composition and function,

63 evidencing Str-mediated ROS production as a primary factor mediating gut-microbiota

64 dysbiosis. In conclusion, a mouse model of social stress disrupts colonic epithelial and mucosal

65 integrity, a response dependent on an intact microbiota and host stress signals. Together these

66 preclinical findings may provide new insight into mechanisms of stress-associated bowel

67 pathologies in humans.

68 Keywords: Stress, epithelium, microbiome, ROS, brain-gut axis 
Allen et al. 3

\section{Introduction}

Psychological stress is associated with disruptions to intestinal physiology. This is supported by studies in humans and animal models that have linked excessive levels of stress to increased risk of enteric infection and inflammatory bowel diseases and syndromes (1-4). The gut microbiota is a large and diverse community of microorganisms that continuously interact with host epithelial and immune components, a relationship that ultimately shapes numerous physiological responses during health and disease (5-8). Stress-induced modifications to the gut microbiota have been documented to occur in humans and across various types of animal models, underscoring a potential nexus between stress and intestinal health (9-11). However, the precise interactions that occur between microbe and host in response to stress are not fully elucidated.

Intestinal epithelial cells (IECs) consist of a diverse range of cells, including absorptive enterocytes, goblet cells, Paneth cells, enteroendocrine cells, and stem cells, that function together to maintain barrier integrity and coordinate proper immune responses to both pathogens and the endogenous microbiota (12). To perform these tasks, IECs have evolved an array of capabilities such as the production and release of mucins, antimicrobial peptides, inflammatory cytokines, and reactive oxygen species (ROS), which help maintain homeostatic immune responses while concurrently preventing overt microbial penetration into host tissue $(6,13,14)$.

87 Despite largely serving a protective role, emerging evidence indicates that abnormal epithelial

8 responses to the endogenous microbiota may be a key component leading to gut dysbiosis and

89 bowel disease manifestation (15). This may be in part due to chronic unabated stimulation of

0 inflammatory pathways within IECs. For instance, hyperactivation of the NFkB pathway through

91 aberrant toll-like receptor (TLR) or nod-like receptor (NLR) signaling on IECs is considered a 
92 major risk factor for inflammatory bowel diseases, such as Crohn's disease and ulcerative colitis

93 (16-18). Consistent with this role, we recently reported that an IEC-specific ablation of the

94 classical NFKB pathway beneficially modified the gut microbiota and inhibited infectious colitis

95 by Citrobacter rodentium in mice (19). This is in contrast to stress exposure, which alters the

96 microbiota and exacerbates gastrointestinal inflammation associated with $C$. rodentium infection

$97(20,21)$. Ultimately, these data lead us to postulate that stressor-induced shifts in the gut

98 microbiota and susceptibly to enteric colitis may be linked through alterations in epithelial

99 physiology.

100 Herein, we utilize a well-validated social disruption stressor (Str) to investigate the effects of

101 psychological stress on the colonic epithelial layer. Our results from conventionally-raised and

102 germ-free animals support the hypothesis that stress induces a global shift in IEC gene

103 transcription indicative of heightened pro-inflammatory, antimicrobial, and ROS signaling; an

104 effect that is dependent on the gut microbiota. Concomitant disruption to the structural integrity

105 of the mucosal layer and amplified systemic markers of bacterial translocation (LBP) signify Str-

106 induced interferences to normal barrier integrity, a phenomenon through which IECs appear to

107 play a central role. Lastly, we demonstrate that Str-induced augmentation in genes involved in

108 IEC ROS production (Duox2 and Nos2) paralleled changes to microbiota catalase activity,

109 together indicating disruptions to IEC-gut microbiota communication with potential implications

110 for gastrointestinal health.

\section{Results}

112 Social Disruption Stress Initiates a Unique Transcriptional Signature within IECs

113 We first exposed conventionally-raised (CONV-R) C57B1/6 mice to a social disruption stressor

114 (Str, $2 \mathrm{~h} / \mathrm{d}$ ) or a home cage control setting (Con) for $6 \mathrm{~d} .12 \mathrm{~h}$ after the final Str exposure, colonic 
115 intestinal epithelial cells (IECs; EpCAM+, CD45-) were isolated and expression profiles analyzed

116 by RNA sequencing. Using the differential gene expression analysis (DESeq2), we identified a

117 broad upregulation in epithelial gene transcription induced by Str (Figure 1a; Volcano plot, 166

118 genes upregulated, 16 downregulated, Log Fold Difference > 0.5, Adj $\mathrm{p}<10^{-5}$ ). Over

119 representation pathway analysis (ORA; NetworkAnalyst; (22)) using the Gene Ontology (GO:BP)

120 database revealed numerous pathways affected by stress (FDR $\mathrm{p}<0.05$; Top 10 enriched pathways

121 shown in Figure 1b). This included Str-induced activation of immune (GO:BP Inflammatory

122 response; genes represented in heatmap shown in Figure 1c) and antimicrobial (GO:BP

123 superoxide signaling and defense response) pathways that occur concomitant to upregulation in

124 pathways related to direct bacterial signaling (GO:BP defense response to bacterium, $N F \kappa B$

125 cascade; FDR $\mathrm{p}<0.05$; Figure 1b). ORA analysis using the KEGG database revealed similar

126 changes in pro-inflammatory and antimicrobial signaling pathways (Figure S1a), including a

127 robust upregulation in genes associated with the NOD-like and Toll-like receptor (NLR, TLR)

128 signaling pathways (FDR p<0.05; Figure S1b-c). In addition, IEC transcriptional profiles revealed

129 a Str-induced downregulation in genes involved in fatty acid degradation and peroxisome

130 biosynthesis that occurred alongside increased expression of genes involved in central carbon

131 metabolism, together indicating coordinated metabolic shifts within IECs in response to Str (FDR

$132 \mathrm{p}<0.05$; Figure S1d-e). Further network visualizations using the GO:BP and KEGG pathways

133 revealed Str-induced coordinated metabolic, hypoxia, wounding response and cytokine-mediated

134 signaling pathways (among others) that corresponded to enhanced immune and antimicrobial

135 signaling (FDR $\mathrm{p}<0.05$; Figure S2a-b). Lastly, we confirmed that protein levels of the

136 antimicrobial peptide "regenerating islet-derived protein $3-\beta$ " REG3 $\beta$ (encoded by Reg3b)

137 reflected changes in IEC gene expression via immunofluorescence $(\mathrm{p}<0.05$; Figure 1d). 
Allen et al. 6

\section{Translocation}

140 We next explored the potential source of enhanced inflammatory and antimicrobial signaling

141 observed in IECs. In the colon, a two-tiered mucus layer maintains a biophysical barrier that

142 prevents excessive bacterial adhesion to IECs and abnormal infiltration into host tissue $(23,24)$.

143 In addition to signs of microbial signaling, we also observed increased expression of genes

144 involved in mucin/glycoprotein biosynthesis within stressor-exposed IECs (DESeq Adj $\mathrm{p}<10^{-5}$;

145 Figure 2a). Therefore, we next asked whether structural changes to the colonic mucus layer may

146 also occur as a result of stress. In a separate cohort of Str-exposed and Con mice ( $\mathrm{n}=12$ /group),

147 we used fluorescence in situ hybridization targeting endogenous bacteria (FISH; EUB338-Cy3)

148 alongside lectin-based staining of the terminal mucus sugar, fucose (UEA1-fluorescein), to

149 visualize potential changes to the integrity of the colonic mucus layer relative to the endogenous

150 microbiota (Figure 2b). Using qualitative and quantitative scoring systems, we found that $6 \mathrm{~d}$ of

151 Str induced a significant disruption to overall mucosal integrity alongside a concurrent reduction

152 in inner mucus layer thickness $(\mathrm{p}<0.05$; Figure 2c-d). While an intact layer with clear separation

153 between the microbiota and IECs was observed in unstressed-control mice, Str-exposed mice

154 exhibited a thinner, more porous and unstructured outer mucus layer with increased evidence of

155 bacterial penetration into the inner mucosal layer (Figure $2 \mathbf{b}$-d). This included evidence of

156 bacterial adhesion to IECs in Str-exposed mice, which rarely occurred in Con mice (Figure S3a).

157 Next, we explored whether Str initiated changes to goblet cell density (the primary mucus

158 producing cell in the colon). However, no changes to total goblet cell number or density per crypt

159 were observed in response to Str (Figure S3b-c). Nevertheless, alongside evidence of bacterial

160 penetration within colonic tissue, Str-exposed mice exhibited higher levels of serum 
Allen et al. 7

161 lipopolysaccharide-binding protein (LBP) compared to Con mice, indicating bacterial

162 translocation occurs in parallel to colonic mucus disruption $(\mathrm{p}<0.05$; Figure 2e).

163 Stress-Induced Changes to the Epithelial Transcriptome is Dependent on an Intact Microbiota

164 In light of combined evidence of altered mucus integrity and elevated signs of direct bacterial

165 signaling within IECs, we next aimed to establish whether the presence of the gut microbiota was

166 essential for mediating the IEC response to Str. First, we exposed a separate and independent

167 cohort of CONV-R mice with an intact microbiota to the social defeat stressor (n=9/group). Using

168 rt-PCR we confirmed that expression of a set of 6 genes (representative of the most altered

169 pathways in the RNA-sequencing dataset: $\operatorname{Reg} 3 b$ (defense response to bacterium), Duox2 and

170 Nos2 (superoxide metabolic processes), Fut2 (glycoprotein biosynthesis), Saal and Il18

171 (inflammatory response) were altered in IECs in response to $\operatorname{Str}(\mathrm{p}<0.05$; Figure 3a). However,

172 when we exposed germ-free mice (GF; $n=9 /$ group) to the social defeat stressor, analysis of these

173 same genes revealed an IEC transcriptional profile entirely unresponsive to the $\operatorname{Str}(\mathrm{p}>0.05$ for all

174 genes; Figure 3b). In addition to lack of differences in IEC expression profiles in response to Str,

175 GF mice did not exhibit any changes to Str serum LBP compared to Con mice $(\mathrm{p}<0.05$; Figure

176 S4). GF mice have an altered mucosal layer and IEC physiology compared to mice that are born

177 with an intact microbiota (CONV-R). This is highlighted by an overall lower expression of ROS

178 (Duox2 and Nos2) inflammatory (Saal) and antimicrobial (Reg3b) genes in GF vs CONV-R mice

179 ( $\mathrm{p}<0.05$; Figure S4b). In light of this distinctive physiology of GF mice, we deemed it necessary

180 to also examine IEC transcriptional responses to stress in CONV-R mice exposed to a broad

181 spectrum antibiotic cocktail (Abx) that significantly depletes microbial load in the distal colon.

182 Similar to what was observed in GF mice, we did not observe a stress-induced upregulation of

183 genes involved in ROS production, antimicrobial defense or innate inflammation in mice treated 
184 with Abx throughout the 6 ds of the Str paradigm (Figure 3c). In fact, in mice treated with Abx,

185 IEC expression of Saal and $I l 18$ were significantly reduced by Str, albeit through currently

186 unknown mechanisms.

187 Stress-Induced IEC Duox2 and Nos2 Relies on Microbial and Host Signals

188 Despite no transcriptional changes of key IEC stress-response genes in GF mice, we deemed it

189 reasonable that endogenous host stress signals may still play a role in mediating IEC physiology,

190 albeit in combination with microbial signals. To explore this hypothesis, we exposed another

191 cohort of GF mice to an identical social disruption paradigm (Str) followed by IEC isolation and

192 culture for $2 \mathrm{~h}$. Cultured IECs were then subjected to an additional $2 \mathrm{~h}$ of immune challenge with

193 bacterial-derived lipopolysaccharide (LPS) or flagellin (FLG) before RNA isolation and gene

194 expression analysis. In analyzing a subset of 6 genes in IECS that were altered by Str in CONV-

195 R, we found that dual oxidase 2 (Duox2) and nitric oxide synthase 2 (Nos2), two genes involved

196 in ROS production, were primed by Str to over-respond to FLG and LPS challenges, respectively

197 (Stress x LPS/FLG p<0.05, Figure 4a,). Stress exposure did not affect the response of other

198 selected genes (Fut2, Saal, Ill8, RegIIIb) to an ex vivo challenges (Str x LPS/FLG, p > 0.05;

199 Figure 4a, Table S1). We reasoned that a Str-induced increase in the expression of toll-like

200 receptor-4 (TLR)-4 (the canonical host receptor for LPS) or toll-like receptor-5 (TLR)-5 (the

201 canonical host receptor for FLG) may underlie the potentiation of Duox2 or Nos2 expression by

202 Str. However, we failed to find any significant Str-induced changes to IEC expression of Tlr4 or

$203 T \operatorname{Tr} 5$ at baseline or in response to an ex vivo bacterial challenge in GF mice (Str x LPS/FLG p>0.05;

204 Figure S5a). To determine if these host-microbiota interactions were dependent on an in-tact

205 microbiota in-vivo, we next used identical stress and ex vivo methods in CONV-R mice, focused

206 on IEC expression of the same target genes described above. Unlike in GF mice, we did not 
observe any interactions of Str and ex vivo immune challenge on IEC gene expression in CONV-

R mice. Nevertheless, we again observed strong main effects of Str on expression of Duox2 and Nos2 (as well as Fut2, Saal and Reg3b) across all ex vivo conditions ( $<<0.05$; Figure S5b and

210 Table S2). We deemed it possible that the difference in GF and CONV-R mice responses to FLG

211 and LPS challenge may be related to Toll-like receptor expression in IECs. However, we failed to

212 find any differences in IEC Tlr4 or Tlr5 expression in GF vs CONV-R mice (Figure S5c). In light

213 of the unique sensitivity of Duox2 to Str and ex vivo challenges, we next investigated whether

214 colonic DUOX2 protein mimicked gene expression changes. Indeed, immunofluorescence of

215 colonic tissue revealed higher levels of colonic DUOX2 protein expression in Str mice, with

216 notable fluorescence signaling observed on the luminal side of the epithelium ( $p<0.05$; Figure $4 \mathbf{b}$ ).

217 Stress Modifies Gut Microbiota Composition Parallel to IEC Transcriptional Changes

218 Changes to epithelial physiology have been linked to gut microbiota dysbiosis $(15,25)$. Thus, we

219 next explored the potential that stressor-induced augmentation in IEC genes (related to

220 inflammation, and antimicrobial and ROS generation) would associate with changes to microbiota

221 composition. To accomplish this, we implemented 16S rRNA gene sequencing to analyze the

222 colonic microbiome of mice from our initial IEC RNA sequencing experiment. Using principle

223 coordinate analysis (unweighted UniFrac), we confirmed the previous findings of our laboratory

$224(10,26)$ and others' $(27,28)$ that stress exposure induces a broad and significant shift to colonic

225 microbiome community structure (ADONIS $\mathrm{p}<0.05$; Figure 5a). Further taxonomic analysis

226 revealed numerus bacterial genera altered by stress, including a robust increase in relative

227 abundance of Muribaculaceae, Enterorhabdus, Marvinbryantia, and Candidatus Arthromitus that

228 occurred alongside a significant decrease in the abundance of genera from the Lachnospiraceae

229 family (FDR p<0.05; Figure 5b). Out of these differentially altered bacteria, we noted that the 
abundance of Muribaculaceae (the most upregulated taxa) covered a wide range within Strexposed mice (4-52\% of total bacteria). In light of this variation, as well as the known

232 communication between IECs and the microbiome, we returned to the RNA sequencing data to

233 determine if the abundance of Muribaculaceae was related to IEC expression profiles. Among

234182 differentially expressed genes in IECs (Con vs. Str, adj $\mathrm{p}<10^{-5}$ ), we found that the expression

235 of both Duox2 and Duoxa2 (a gene encoding the maturation protein for DUOX2), as well as Nos2,

236 were associated with Muribaculaceae abundance (Spearman rho > 0.63, p<0.05; Top 20

237 differentially expressed IEC genes vs. Muribaculaceae shown in Figure 5c-d).

238 Stress-Induced Modifications to Gut Microbiota Function and Activity Reflects Adaptations to

239 IEC ROS Generation

240 DUOX2 produces hydrogen peroxide $\left(\mathrm{H}_{2} \mathrm{O}_{2}\right)$, a ROS that, if produced at high levels, can be toxic

241 to colonic anaerobic bacteria that do not contain the $\mathrm{H}_{2} \mathrm{O}_{2}$ degrading enzyme, catalase $(29,30)$.

242 Thus, in light of the strong parallels between Duox2 and Duoxa2 expression and gut microbiome

243 composition, we next aimed to establish whether $\operatorname{Str}$ ( $\mathrm{n}=3$ /group) would shift the function of the

244 microbiota towards a state of increased resistance to ROS production by IECs. Using metagenomic

245 sequencing of distal colonic contents, we observed a Str-induced trend for increased overall

246 catalase gene copy abundance, primarily mapping to Bacteroides and Parabacteroides genera

$247(\mathrm{p}=0.10$; Figure 6a). Given this tendency, we next considered whether catalase enzyme activity

248 would also increase as a result of Str. Indeed, in an independent cohort of mice exposed to the Str

249 paradigm ( $\mathrm{n}=5$ /group), we found augmented catalase activity within the colonic luminal contents

250 of Str-exposed mice compared to Con mice ( $<<0.05$; Figure 6b).

251 Discussion 
Exposure to psychological stress alters the microbiota and predisposes individuals to 253 increased risk of enteric infections and bowel diseases and conditions $(1-3,9,20,31,32)$.

254 However, stressor-induced modifications to the gut microbiota and gastrointestinal health have not

255 been surveyed in context of intestinal epithelial cells (IECs), which have a unique role in: 1)

256 maintaining a physical barrier between microbe and host, 2) relaying microbial signals to the

257 immune system, and 3) producing bioactive molecules that subsequently modify the gut

258 microbiota (33-35). In this study, we provide evidence that a mouse model of social defeat stress

259 (Str) results in broad and physiologically relevant shifts to IEC physiology, underscored by an

260 upregulation in antimicrobial, pro-inflammatory, and ROS-generating pathways that occur

261 concomitantly to mucosal disruption, signs of systemic bacterial translocation, and functional

262 changes to the gut microbiota.

263 Evidence of coordinated antimicrobial and immune signaling was present in Str-exposed

264 IECs. This was apparent by transcriptional network analysis, which revealed an IEC gene signature

265 supporting heightened innate immune signaling downstream of toll-like receptor (TLR) and

266 nucleotide-binding oligomerization domain-like receptor (NLR) pathways. Constitutively

267 expressed bacterial components such as LPS, FLG, and muramyl dipeptides bind TLRs and NLRs

268 to activate the NFkB pathway, which ultimately enhances the expression of genes involved in

269 innate immune signaling and ROS generation, such as Saal, Nos2 and Duox2 (36). This

270 enhancement in IEC TLR/NLR-to-NFאB signaling likely has important implications for

271 understanding how stress predisposes to enteric infection and inflammatory bowel disease. Indeed,

272 studies have demonstrated that hyperactivation of the NFKB pathway contributes to aberrant

273 inflammatory responses to enteric infection and colitis $(37,38)$. In addition, recent data from our

274 laboratory showed that ablation of the classical NFKB pathway in IECs conferred increased host 
protection against a colonic Citrobacter rodentium infection challenge (19). This is in contrast to stress, which exacerbates $C$. rodentium infection $(3,20,21)$. Further studies are needed to unravel

277 the mechanistic underpinnings of IEC NFאB signaling in response to stress and its potential role 278 in mediating gastrointestinal infection and/or inflammatory bowel disease. and physical protection against aberrant microbial signaling (23). We found that stress reduced the

281 thickness and disrupted the integrity of these mucus layers. Morphological changes to the mucus 282 coincided with altered transcription of genes involved in glycoprotein biosynthesis (e.g. Mucl, 283 Muc13) and mucin glycosylation (e.g. Fut2, St8sial) in IECs. While mechanisms underlying 284 stress-induced mucus disruption remain unknown, it is important to note these transcriptional and 285 morphological changes did not occur in GF mice, highlighting a key role of an intact microbiota 286 in modifying the mucus layer during Str. Indeed, other research has identified specific members 287 of the microbiota, such as Bacteroides thetaiotamicron, that are directly responsible for modifying 288 mucus integrity and barrier function $(39,40)$, some of which are associated with mucus disruption 289 during inflammatory bowel diseases like ulcerative colitis and Crohn's disease $(40,41)$. In this 290 study, it is feasible that Muribaculaceae, which was highly upregulated by stress and was recently 291 found to exhibit robust mucus degrading properties (42), may be driving changes to mucus 292 integrity and bacterial translocation observed in response to stress. Indeed, our data coincide with 293 previous reports of social stress-induced bacterial translocation $(20,43)$ and highlight the need for 294 further research into the role of colonic mucosal integrity as a mechanism by which endogenous 295 microbes (or immune-stimulating bacterial components) reach host circulation during stress. 296 Future studies using gnotobiotic models (monocolonization or multi-strain colonization) will be 
needed to help ascertain the specific microbes responsible for stress-induced IEC transcriptional responses, mucosal layer degradation and barrier disruption. increased activity of IECs. This includes Reg3b and Reg3g, antimicrobial C-type lectins whose transcription activity within IECs are strongly upregulated by exogenous signals $(44,45)$. While not a focus of this study, cytokines released in response to bacterial signaling by local immune cells (e.g. innate lymphoid cells \& Th17 cells) can activate anti-microbial defense pathways in epithelial cells $(46,47)$. In support of this, our transcriptome data revealed Str-induced gene transcription profiles centered around activation of the Janus kinase/Signal transducer of activated (among other cytokines) and is the primary route of $\operatorname{Reg} 3 b$ and $\operatorname{Reg} 3 g$ transcription in IECs (48). The specific effects of stress on the colonic immune cell niche, however, remains understudied. Nevertheless, our network analysis of IEC expression profiles revealed Str-induced upregulation in genes involved in Th17 differentiation (e.g. Saal/3), highlighting a potential role of IECs in

311 driving local changes to the innate and adaptive immune cell compartments, which may ultimately

312 feedback to control IEC physiology (35). Future studies will need to delineate the mechanisms 313 and implications of an immune-epithelial cell axis in response to stress.

In germ-free mice IEC Duox2 and Nos2 expression (while unchanged at baseline) were

315 uniquely primed by host stress signals to respond to bacterial (Flagellin and LPS) challenge. Duox2

316 encodes DUOX2 protein, which is a member of the NAD(P)-H dependent oxidase family that is

317 highly expressed on IECs and is the primary contributor of host hydrogen peroxide $\left(\mathrm{H}_{2} \mathrm{O}_{2}\right)$

318 production in the mammalian GI tract $(49,50)$. Nos 2 encodes inducible nitric oxide synthase

319 (iNOS), an enzyme that produces nitric oxide (NO) in response to inflammatory signals. NO is a 
relatively weak free radical, but contributes to toxicity in the gut by forming peroxynitrite $\left(\mathrm{NO}_{3}{ }^{-}\right)$

321 (51, 52). DUOX2 and iNOS mediated ROS and RNS production represent important anti-bacterial

322 defense pathways within the mammalian colon $(15,53)$. For example, DUOX2-mediated ROS

323 generation was shown to be required for an adequate NOD2-mediated antimicrobial response to

324 Listeria monocytogenes challenge (25). Meanwhile, iNOS mediated NO production limits growth

325 of enteric pathogens such as Salmonella Tymphimurium (54). However, while acute DUOX2 and

326 iNOS signaling appears important for antimicrobial defense to enteric pathogens, unabated and

327 chronic ROS signaling may cause long-term disruption to the gut microbiota and the epithelial

328 niche. This is supported by a growing body of literature linking chronic DUOX2 and iNOS

329 signaling to inflammatory bowel disease (IBD) and microbial dysbiosis $(53,55,56)$. For example,

330 both colonic DUOX2 and iNOS are upregulated during the early onset $\operatorname{IBD}(57,58)$ while DUOX2

331 is highly responsive to a dysbiosis microbiome isolated from IBD patients (15). Future studies that

332 delineate the role of stress-induced modifications to DUOX2 and iNOS activity may help unravel

333 the complex etiology of stress-associated inflammatory bowel diseases.

Catalase, an enzyme that speeds the breakdown of $\mathrm{H}_{2} \mathrm{O}_{2}$ into oxygen and water, represents

335 a main line of bacterial defense against host-mediated ROS generation (59). However, catalase is

336 not expressed by many commensal anaerobic microbes that reside in the colonic niche, leaving

337 them vulnerable to excess ROS production $(60,61)$. In the case of stress, we hypothesized that

338 high production of $\mathrm{H}_{2} \mathrm{O}_{2}$ through enhanced DUOX2 signaling may deplete catalase deficient

339 microbiota species. In line with this premise, we found that each taxa reduced by Str, including

340 bacteria from Lachnospiracae family, are almost entirely catalase negative. Conversely, species

341 within the most prominently upregulated taxa in response to stress, species from the family

342 Muribaculaceae (previously named S24-7), expresses catalase (62). Based off of these findings, it 
343 is tempting to speculate that catalase-positive bacteria are able to survive Str-induced upregulation

344 in DUOX2 activity and subsequent $\mathrm{H}_{2} \mathrm{O}_{2}$ production, whereas bacteria without the enzyme are

345 depleted. Indeed our data showing increased catalase enzyme activity in the colonic lumen of Str-

346 exposed mice support the idea that catalase-positive bacteria, regardless of taxonomy, bloom in

347 response to Str. In fact, previous work in mice (26) and in humans $(4,9)$ has shown that stress

348 exposure is associated with increased abundance of Bacteroides spp. and Parabacteroides spp.,

349 oxygen tolerant anaerobic commensals found in the mammalian microbiome, both of which

350 express catalase (30). In addition, IEC DUOX2 activity can promote a competitive niche for

351 catalase-positive facultative anaerobes such as E. coli and C. rodentium, while inducing a hostile

352 environment for commensals such as Lactobacillus spp. (14). This is consistent with stress-

353 induced reductions in Lactobacillus spp. abundance and increased C. rodentium colonization (3,

$35463,64)$. Future studies are needed to further unravel how the microbiota and pathogens respond to

355 enhanced ROS-generation by IECs during stress.

The effects of psychological stress on the mammalian gut and its microbiota are only

357 beginning to be explored. In this study, we show that a mouse model of psychological social stress

358 induces a robust and reproducible transcriptional signature within IECs indicative of enhanced

359 pro-inflammatory, antimicrobial, and ROS signaling. These effects, which were reliant on an intact

360 microbiota, manifested in morphological changes to the mucus layer and signs of bacterial

361 translocation, underscoring the significance of the intestinal epithelial layer as a central component

362 to stress physiology. We also uncovered a potential role of epithelial cells as mediators of gut

363 microbiota function, evidenced by Str-induced increase in microbe-specific ROS detoxifying

364 activity (catalase) that paralleled ROS-generating capacity of IECs. Together, our data uncover a 
maladaptation to psychosocial stress involving the gut microbiota and intestinal epithelial cells that provides a strong link to enteric infection and bowel disease manifestation.

\section{Materials and Methods}

\section{Animals}

Adult male C57BL/6NCrl strains of Mus musculus (Charles Rivers Laboratories, Wilmington,

MA) between 6-8 weeks of age were used in the study. Animals were given ad libitum access to water and autoclaved chow throughout all experiments (12 $\mathrm{h}$ light cycle; lights on at 06:00).

372 Separate cohorts of CONV-R mice were used in the following experiments: 1. IEC RNA

373 sequencing $(\mathrm{n}=10 /$ group $), 2$. Mucosal integrity $(\mathrm{n}=9 /$ group $), 3$. DUOX2 IF staining $(\mathrm{n}=$

374 6/group) 4. Metagenomics ( $n=3 /$ group) and 5. Catalase activity $(n=5 /$ group). 6. broad

375 spectrum antibiotics ( $\mathrm{n}=6$ /group). Germ-free mice ( 4 wks old) were purchased from Charles

376 River. To prevent microbial contamination germ-free animals were kept in Sentry sealed positive

377 pressure cages (Allentown, Allentown, $\mathrm{NJ}$ ) for a 2-week acclimation period and over the course

378 of the study. Germ free sterility was confirmed by following the standard contamination protocol

379 used by the National Gnotobiotic Rodent Resource Center (NGRRC) at UNC-Chapel Hill

380 (UNC). A separate cohort of GF mice were used for the following experiments: 1. IEC gene

381 expression $(n=9 /$ group) and 2 . IEC ex vivo challenge $(n=6 /$ group $)$, totaling two separate

382 cohorts of GF mice. All experimental procedures were conducted in the Animal Resources Core

383 (ARC) facility at Research Institute at Nationwide Children's Hospital or at the Animal Care

384 Facility at the University of Illinois at Urbana-Champaign with the approval of the Research

385 Institutional Animal Care and Use Committees at each institution (NCH-Protocol \#AR15-00046

386 and UIUC-Protocol \# 20241).

\section{$387 \quad$ Social disruption stressor}


Social disruption stress (Str) was completed by placing an aggressor mouse (retired breeder

C57BL/6NCrl) into the cage with 3 resident mice of the same strain for $2 \mathrm{~h}$ between 16:30-18:30 subordinate behaviors as described previously (26). This protocol was repeated for 6 consecutive

$392 \mathrm{~d}$ with animal sacrifice and tissue collection occurring 12-15 $\mathrm{h}$ after the final stressor. These mice

393 were closely monitored, but none of the mice needed to be removed for excessive wounding

394 using criteria previously described (22). Mice in the control condition were not handled

395 throughout the experiment. GF aggressors were checked for microbial contamination by PCR

396 and culture in an identical manner to experimental mice

398 A broad-spectrum antibiotic cocktail ( 40mg/kg/day, ampicillin $33 \mathrm{mg} / \mathrm{kg} / \mathrm{day}$, metronidazole

$39921.5 \mathrm{mg} / \mathrm{kg} /$ day, vancomycin $4.5 \mathrm{mg} / \mathrm{kg} /$ day; Sigma-Aldrich) was provided in drinking water

400 throughout the 6ds of the Str paradigm.

\section{$401 \quad$ Intestinal epithelial cell isolation and culture}

402 Colons were removed from animals immediately after sacrifice, opened longitudinally, washed

403 with PBS thoroughly and cut into $5 \mathrm{~mm}$ pieces. Tissue was then placed in a pre-digestion

404 solution (1x HBSS, 5 mM EDTA, 1mM DTT, 5\% FBS with Antibiotic/Antimycotic solution

405 (Sigma Aldrich, St. Louis, MO)) and rotated for $20 \mathrm{~min}$ at $37^{\circ} \mathrm{C}$. After brief vortexing at high

406 speed (10 s), the tissue homogenate was filtered with a $100 \mu \mathrm{M}$ mesh filter with the resulting

407 pass through (containing IEC fraction) placed on ice. The remaining colon pieces were placed in

$40820 \mathrm{~mL}$ of fresh pre-digestion buffer and rotated again. These steps were repeated 3 consecutive

409 times with pass through stored on ice after each rotation to ensure adequate IEC removal from

410 lamina propria. Next, single cell suspensions containing the IEC fraction were diluted to $10^{8}$ 
Allen et al. 18

411 cells/mL in MACs buffer (0.5\% BSA 2mM EDTA) before being processed with the Miltenyi

412 Dead Cell Removal Kit (Miltenyi Biotec, Auburn, CA) per manufacturer's instructions. After a

413 wash step, live cells were incubated with CD45 magnetic beads for 10 min before being passed

414 through Miltenyi LS columns per manufacturer's instructions. After an additional wash step, the

$415 \mathrm{CD}^{-}$cell fraction (107-10 ${ }^{8}$ cells) was incubated with $\mathrm{EpCAM}^{+}$beads for 10 min before again

416 passing through LS columns per manufacturer instructions. Resulting cells were collected for

417 RNA isolation. For ex vivo experiments, cells were plated in 24 -well cell culture plates at $2 \times 10^{5}$

418 cells/well and incubated $\left(5 \% \mathrm{CO}_{2}\right)$ at $37^{\circ} \mathrm{C}$ for $2 \mathrm{~h}$. Cells were then treated with saline (PBS),

419 LPS (E. coli O55:B55 (1 $\mu \mathrm{g} / \mathrm{mL})$; Sigma Aldrich) or FLG (Ultrapure-Salmonella typhimurium

420 (200ng/mL); Invitrogen, San Diego, CA) and incubated at $37^{\circ} \mathrm{C}$ for another $2 \mathrm{~h}$ before RNA

421 isolation.

\section{$422 \quad$ RNA sequencing}

423 IEC RNA was isolated using the PureLink RNA Mini Kit (Thermo Fisher Scientific, Waltham,

424 MA) according to manufacturer's instructions. Following assessment of the quality of total RNA

425 using Agilent 2100 bioanalyzer and RNA Nano Chip kit (Agilent Technologies, Santa Clara,

426 CA), rRNA was removed from 2000 ng of total RNA with Ribo-Zero rRNA removal kit specific

427 for Human/Mouse/Rat. To generate directional signal in RNA seq data, libraries were

428 constructed from first strand cDNA using ScriptSeq ${ }^{\mathrm{TM}}$ v2 RNA-Seq library preparation kit

429 (Epicentre Biotechnologies, Madison, WI). Briefly, 50 ng of rRNA-depleted RNA was

430 fragmented and reverse transcribed using random primers containing a 5' tagging sequence,

431 followed by 3'end tagging with a terminal-tagging oligo to yield di-tagged, single-stranded

432 cDNA. Following purification by a magnetic-bead based approach, the di-tagged cDNA was

433 amplified by limit-cycle PCR using primer pairs that anneal to tagging sequences and add 
434 adaptor sequences required for sequencing cluster generation. Amplified RNA-seq libraries were

435 purified using AMPure XP System (Beckman Coulter, Brea, CA). Quality of libraries were

436 determined via Agilent 2200 TapeStation using High Sensitivity D1000 tape and quantified

437 using Kappa SYBR®Fast qPCR kit (KAPA Biosystems, Inc, Wilmington, MA). Approximately

$438 \quad 60-80$ million paired-end $150 \mathrm{np}$ sequence reads were generated per sample using the Ilumina

439 HiSeq 4000 sequencer.

$440 \quad$ RNA-seq data analysis

441 Each sample was aligned to the GRCm38.p4 assembly of the mouse reference from NCBI using

442 version of $2.5 .1 \mathrm{~b}$ of the RNA-Seq aligner STAR

443 (http://bioinformatics.oxfordjournals.org/content/29/1/15). Transcript features were identified

444 from the general feature format (GFF) file that came with the assembly from the NCBI. Feature

445 coverage counts were calculated using HTSeq (http://www-

446 huber.embl.de/users/anders/HTSeq/doc/count.html). The raw RNA-Seq gene expression data

447 was normalized, and post-alignment statistical analyses and figure generation were performed

448 using DESeq2 (http://genomebiology.com/2014/15/12/550) and analyzed by the open-source

449 NetworkAnalyst 3 software (22). Variance and low abundance filters were set at 15 and 4,

450 respectively. Samples were normalized to Log2-counts per million reads. Normalized read

451 counts were then analyzed (Con vs. Str) by differential expression analysis based on the binomial

452 distribution (DESeq2 (65)) with significance set at $\log _{2}$ Fold Change $>0.5$ and an Adj $\mathrm{p}<10^{-5}$.

453 Over representation pathway (ORA) heatmap clustering, and network analysis was performed

454 through NetworkAnalyst (22) with significantly altered genes (DeSeq2 Adj $\mathrm{p}<10^{-5}$ ) as input

455 variables. Differences in pathway abundance were deemed significant at FDR $\mathrm{p}<0.05$ through

456 NetworkAnalyst. 
Allen et al. 20

\section{Collection and processing for immunofluorescence and FISH staining}

Immediately after sacrifice, sections of the mid-colon were collected (with intestinal contents left in place) and tissues were fixed by immersion in methanol Carnoy's solution (60\% methanol, $30 \%$ chloroform, $10 \%$ acetic acid) for $48-96 \mathrm{~h}$, followed by two successive washes each in methanol for $35 \mathrm{~min}$, ethanol for $30 \mathrm{~min}$, and xylene for $25 \mathrm{~min}$. Cassettes were then submerged in melted paraffin at $68^{\circ} \mathrm{C}$ for $1 \mathrm{~h}$, removed, and kept at RT until sectioning. Paraffin blocks were cut into $4 \mu \mathrm{m}$-thick sections and deparaffinized prior to immunofluorescence or FISH/mucus staining. For cryosectioning (DUOX2 staining), samples were snap-frozen in Tissue-Tek O.C.T. compound (Andwin Scientific, Woodland Hills, CA) and immediately sectioned at $8 \mu \mathrm{m}$ thickness on a cryostat.

\section{Immunofluorescence}

Sections were deparaffinized in $100 \%$ xylene for $10 \mathrm{~min}$ and $50 \%$ xylene/50\% ethanol for $5 \mathrm{~min}$ followed by successive 5 min washes in 100\%, 95\%, 75\%, 50\%, 25\% and 0\% EtOH/PBS solution. Slides were then placed in citrate buffer antigen retrieval solution (pH 6.0) with $0.5 \%$ Tween-20 in a $90^{\circ} \mathrm{C}$ water bath for $20 \mathrm{~min}$. After allowing slides to cool in running $\mathrm{H}_{2} \mathrm{O}$, slides were dried and incubated in permeabilization buffer (0.3\% Triton-X, $1 \%$ BSA/PBS) for $30 \mathrm{~min}$ at room temperature followed by another 3 wash steps with PBS. Slides were then incubated in permeabilization buffer containing the primary REG3 $\beta$ antibody (1:250 dilution; R\&D systems, Minneapolis, MN) overnight (16 h). After 3 consecutive washes, the slides were incubated in permeabilization buffer containing secondary antibody, anti-rabbit IgG-AlexaFluor 488 (1:500 dilution; Thermo Fisher Scientific), for $1 \mathrm{~h}$ in the dark. After an additional 3 washes (PBS), slides were dried and incubated with Prolong Gold Anti-Fade DAPI solution (Thermo Fisher Scientific) for $2 \mathrm{~h}$ in the dark prior to slide curation and imaging. 
DUOX2 staining was completed on frozen sections as previously described (15). Briefly,

thawed $8 \mu \mathrm{m}$ sections were briefly fixed in $4 \%$ freshly prepared formaldehyde for 5 min, washed

twice in PBS, and then blocked with $20 \%$ donkey serum in PBS. Primary pan-DUOX antiserum

487 After 3 consecutive washes anti-rabbit Alexa Fluor-568 conjugated antibodies (1:500; Thermo

488 Fisher Scientific) were applied for $2 \mathrm{~h}$ before counterstaining with DAPI.

\section{FISH and mucus staining}

490 Slides were deparaffinized by an initial incubation of slides at $60^{\circ} \mathrm{C}$ for $10 \mathrm{~min}$ and then

491 incubated in xylene substitute solution twice for $10 \mathrm{~min}$ with the first solution pre-warmed to

$49260^{\circ} \mathrm{C}$. Slides were then washed in $99.5 \%$ ethanol for $5 \mathrm{~min}$ and left to dry. For hybridization,

493 slides were incubated in a pre-warmed hybridization solution (5M NaCL 1M Tris-Hcl (pH 7.4),

$4941 \%$ sodium dodecyl sulfate and $10 \%$ formamide) containing the FISH probe (EUB338-Cy3; see

495 Table S3) before being placed in a sealed humid chamber at $49^{\circ} \mathrm{C}$ overnight. Slides were

496 incubated with FISH washing buffer $(0.9 \mathrm{M} \mathrm{NaCl}, 20 \mathrm{mM}$ Tris- $\mathrm{HCl}(\mathrm{pH} 7.4))$ preheated to $49^{\circ} \mathrm{C}$

497 for $10 \mathrm{~min}$, and washed three times in PBS. For mucus (fucose) staining, slides were then

498 incubated with 1:500 fluorescein labeled Ulex Europaeus Agglutinin-1 (UEA-1-

499 fluorescein,Vector Labs, Burlingame, CA) for $1 \mathrm{~h}$ in the dark. After 3 washes, slides were

500 incubated with Prolong Gold Anti-Fade DAPI solution (Thermo Fisher Scientific) for at least $2 \mathrm{~h}$

501 in the dark prior to slide curation and imaging.

\section{Serum LPS-binding Protein}

503 Serum LPS-binding protein concentrations were determined by a commercially available ELISA

504 kit via manufacturer's instructions (Hycult Biotec, Uden, Netherlands). 
Allen et al. 22

\section{Semi-quantitative Real-Time PCR}

IEC RNA was isolated using the PureLink RNA Mini Kit (Thermo Fisher Scientific) according to manufacturer's instructions. Complementary DNA was synthesized with a reverse transcriptase kit (Thermo Fisher Scientific). Power SYBR Green Master Mix (Thermo Fisher Scientific) with primers (Fwd and Rv, Integrated DNA Technologies, Coralville, IA) listed in Table S3 used together in PCR reactions. Differences in gene expression were determined by Real-Time PCR (Quantstudio 5, Thermo Fisher Scientific). Relative expression was determined using the delta-delta cycle threshold method $\left(\mathrm{dd} C_{\mathrm{t}}\right)$.

\section{S rRNA Gene Sequencing and Analysis}

Intestinal contents were collected directly from the colon immediately after sacrifice and frozen at $-80^{\circ} \mathrm{C}$. Contents were homogenized and DNA was extracted $(\sim 10 \mathrm{mg})$ using a QIAamp Fast DNA Stool Mini Kit (Qiagen, Hilden, Germany) following manufacturer's instructions, with slight modifications. Contents were incubated for $45 \mathrm{~min}$ at $37^{\circ} \mathrm{C}$ in lysozyme buffer $(22 \mathrm{mg} / \mathrm{ml}$ lysozyme, $20 \mathrm{mM}$ TrisHCl, $2 \mathrm{mM}$ EDTA, 1.2\% Triton-x, $\mathrm{pH}$ 8.0), before homogenization for $150 \mathrm{~s}$ with $0.1 \mathrm{~mm}$ zirconia beads. Samples were incubated at $95^{\circ} \mathrm{C}$ for $5 \mathrm{~min}$ with InhibitEX Buffer, then incubated at $70^{\circ} \mathrm{C}$ for 10 min with Proteinase $\mathrm{K}$ and Buffer AL. Following this step, the QIAamp Fast DNA Stool Mini Kit isolation protocol was followed, beginning with the ethanol step. DNA was quantified with the Qubit 2.0 Fluorometer (Life Technologies, Carlsbad, CA) using the dsDNA Broad Range Assay Kit. Amplified PCR libraries were sequenced from both ends of the $250 \mathrm{nt}$ region of the V3-V4 16S rRNA hypervariable region using an Illumina MiSeq. DADA2 and Quantitative Insights into Microbial Ecology [QIIME] 2.0 (66) were utilized for amplicon processing, quality control and downstream taxonomic assignment using the ribosomal RNA database SILVA version 138 (67). The EMPeror software package was used 
529 for three dimensional principle coordinates plotting of microbiome data ( $\beta$ - diversity;

530 Unweighted Unifrac) (68).

\section{Metagenomic Sequencing and Analysis}

532 DNA for metagenomic sequencing was extracted from 6 colonic content samples from a separate

533 cohort of mice exposed to the stress paradigm ( $\mathrm{n}=3$ /group) and sequenced at the Genomics

534 Shared Research facility at The Ohio State University (Columbus, OH). Prior to library

535 generation, microbial DNA enrichment was performed using the NEBNext Microbiome DNA

536 Enrichment kit (New England BioLabs, Ipswich, MA) per manufacturers protocol. Libraries

537 were generated using the NExtera XT Library System in accordance with the manufacturer's

538 instructions. Genomic DNA was sheared by sonication and fragments were end-repaired.

539 Sequencing adapters were ligated, and library fragments were amplified with five cycles of PCR

540 before solid-phase reversible immobilization size selection, library quantification, and validation.

541 Libraries were sequenced on the Illumina HiSeq 4000 platform. All raw reads were trimmed

542 from both the 5' and 3' ends with Sickle before downstream processing. 150 bp reads were

543 processed downstream by HUMAnN 2.0. Briefly, the HUMANn2 core function was run using

544 nucleotide mapping and translated search against the UniRef 90 database. To account for

545 differences in sequencing depth, the resulting organism specific gene and pathway abundances

546 were normalized to total reads (copies/million). For this analysis, relative catalase levels were

547 tabulated on a per-taxa and total gene abundance basis and then analyzed across Str groups.

\section{Catalase Activity Assay}

549 Colonic content samples that were flash frozen after sacrifice were thawed on ice and weighed to $550 \sim 100 \mathrm{mg} .1 \mathrm{~mL}$ of PBS was precisely added to every $100 \mathrm{mg}$ of stool before being broken up by

551 vigorous pipetting. Samples were vortexed for 1 minute and then spun at $10,000 \mathrm{xg}$ for $5 \mathrm{~min}$. 
552 To disrupt bacterial cell walls, contents were incubated for $45 \mathrm{~min}$ at $37^{\circ} \mathrm{C}$ in lysozyme buffer

$553\left(22 \mathrm{mg} / \mathrm{ml}\right.$ lysozyme, $20 \mathrm{mM}$ TrisHCl, $2 \mathrm{mM}$ EDTA, $1.2 \%$ Triton-x, $\mathrm{pH}$ 8) for $45 \mathrm{~min}$ at $37^{\circ} \mathrm{C}$.

554 Next, $300 \mathrm{mg}$ of autoclaved beads ( $0.1 \mathrm{~mm}$ zirconia) were added to each sample before bead

555 beating for $3 \mathrm{~min}$. Samples were then spun down at 12,000 x g for $15 \mathrm{~min}$. Supernatant was

556 removed and stored on ice until catalase assay was performed. Catalase activity was determined

557 using a fluorometric-based catalase activity kit according to manufactures instructions (Abcam,

558 Cambridge, MA). Catalase activity was calculated as nmol/min/mL.

\section{Image Quantification}

560 Immunostained and/or lectin stained cross-sectioned colon samples were analyzed by a LSM 880

561 confocal microscope (Zeiss Microscopy, Jena, Germany). After image capture, sections were

562 analyzed for protein quantification through fluorescence intensity analysis in ImageJ. Mucus

563 integrity was analyzed on FISH/mucus stained sections by a blinded observer with the following

564 scoring system: $0=$ normal mucus thickness with bacterial adherence only on outer mucus layer,

$5651=$ normal mucus thickness and integrity with minor bacterial penetration to inner mucus layer,

$5662=$ moderate outer mucus layer depletion with moderate bacterial penetration to inner mucus

567 layer, $3=$ moderate depletion of outer and inner layer integrity with high bacterial penetration to

568 inner mucus layer and moderate adherence to epithelium, 4 = major mucus depletion of outer and

569 inner layer with substantial bacterial adherence to epithelium. Inner layer mucus thickness was

570 analyzed by ImageJ software. Goblet cells were counted and analyzed by total number and

571 density per crypt. All measurements were made by a blinded observer and averaged across 5

572 randomly chosen crypt regions.

\section{Statistical Analyses}


574 Student t-tests were used to analyze differences between Con and Str groups. Two-factor ANOVA

575 with Str (in vivo) and LPS/FLG (ex vivo) as variables was used to analyze data from ex vivo IEC

576 experiments. Tukey's post-hoc was used for multiple comparison testing. Differences in

577 microbiome $\beta$-diversity was determined through UniFrac distance metric (69) and analyzed by

578 permutational multivariate analysis (ADONIS). Spearman rho non-parametric analysis was

579 implemented to analyze associations between IEC expression profiles and the abundance of

580 Muribaculaceae. The Benjamini-Hochberg false discovery rate (FDR) method was implemented

581 to avoid type-1 error in all cases with multiple testing. Data is expressed as mean +/- SEM.

582 Statistical alpha was set a priori to 0.05 for all analyses.

\section{Randomization and Blinding}

584 ARRIVE guidelines for preclinical animal experiments were followed (70). All mice were 585 randomly assigned to Str groups prior to the initiation of each experiment. Blinded observers were

586 utilized for all staining quantification and histological scoring.

\section{Ethics Statement}

588 All animals used in this study were approved by the IACUC at Nationwide Children's Hospital.

589 The authors report no competing interests.

\section{Data Availability Statement}

591 The datasets used and/or analyzed during the current study are available from the corresponding

592 authors on reasonable request. RNA-sequencing and 16S rRNA gene data will be deposited on

593 NCBI.

594 Acknowledgements

596 The authors thank X. De Deken, F. Minot and H. Grasberger for providing DUOX antibodies.

\section{Declaration of Interests}


Allen et al. 26

598 The authors declare no conflicts of interest.

\section{CONTRIBUTORS}

600 J.M.A. planned and performed experiments, collected and analyzed data, and wrote the

601 manuscript. A.R.M. planned and performed experiments, collected data, and edited the manuscript

602 R.M.J. P.C.B, C.H.L, M.W. and C.L performed experiments and edited the manuscript. B.R.L.

603 and R.D analyzed data and edited the manuscript. P.W. collected data and edited the manuscript.

604 M.T.B. planned experiments, analyzed data and edited the manuscript.

605 FUNDING

606 This work was supported by a Ruth L. Kirschstein National Research Service T32DE014320 to J.

607 Allen. Internal funding from UIUC allocated to J. Allen. NIH grant AT006552-01A1 to M. Bailey,

608 and internal funding from the Abigail Wexner Research Institute at Nationwide Children's

609 Hospital to J. Allen and M. Bailey.

$610 \quad$ List of abbreviations:

611 IEC: Intestinal epithelial cell

612 ROS: Reactive oxygen species

613 CONV-R: Conventionally-raised

614 GF: Germ-free

$615 \quad I l:$ Interleukin

616 Saa: Serum amyloid a

617 Duox: Dual oxidase

618 Reg3: Regenerating islet-derived protein 3

619 Nos2: nitric oxide synthase-2

$620 \quad$ References 
621 1. Mawdsley JE, Rampton DS. Psychological stress in IBD: new insights into pathogenic

622 and therapeutic implications. Gut. 2005;54(10):1481-91.

623 2. Goodhand JR, Wahed M, Mawdsley JE, Farmer AD, Aziz Q, Rampton DS. Mood

624 disorders in inflammatory bowel disease: relation to diagnosis, disease activity, perceived stress,

625 and other factors. Inflamm Bowel Dis. 2012;18(12):2301-9.

626 3. Bailey MT, Dowd SE, Parry NM, Galley JD, Schauer DB, Lyte M. Stressor exposure

627 disrupts commensal microbial populations in the intestines and leads to increased colonization by

628 Citrobacter rodentium. Infect Immun. 2010;78(4):1509-19.

629 4. Peter J, Fournier C, Durdevic M, Knoblich L, Keip B, Dejaco C, et al. A Microbial

630 Signature of Psychological Distress in Irritable Bowel Syndrome. Psychosom Med.

$6312018 ; 80(8): 698-709$.

632 5. Thaiss CA, Zmora N, Levy M, Elinav E. The microbiome and innate immunity. Nature.

$6332016 ; 535(7610): 65-74$.

634 6. Adolph TE, Tomczak MF, Niederreiter L, Ko HJ, Bock J, Martinez-Naves E, et al.

635 Paneth cells as a site of origin for intestinal inflammation. Nature. 2013;503(7475):272-6.

636 7. Pickard JM, Maurice CF, Kinnebrew MA, Abt MC, Schenten D, Golovkina TV, et al.

637 Rapid fucosylation of intestinal epithelium sustains host-commensal symbiosis in sickness.

638 Nature. 2014;514(7524):638-41.

639 8. Schiering C, Wincent E, Metidji A, Iseppon A, Li Y, Potocnik AJ, et al. Feedback control

640 of AHR signalling regulates intestinal immunity. Nature. 2017;542(7640):242-5.

641 9. Mackner LM, Hatzakis E, Allen JM, Davies RH, Kim SC, Maltz RM, et al. Fecal

642 microbiota and metabolites are distinct in a pilot study of pediatric Crohn's disease patients with

643 higher levels of perceived stress. Psychoneuroendocrinology. 2020;111:104469. 
644 10. Bailey MT, Dowd SE, Galley JD, Hufnagle AR, Allen RG, Lyte M. Exposure to a social

645 stressor alters the structure of the intestinal microbiota: implications for stressor-induced

646 immunomodulation. Brain Behav Immun. 2011;25(3):397-407.

647 11. Bailey MT, Lubach GR, Coe CL. Prenatal stress alters bacterial colonization of the gut in 648 infant monkeys. J Pediatr Gastroenterol Nutr. 2004;38(4):414-21.

649 12. Arora P, Moll JM, Andersen D, Workman CT, Williams AR, Kristiansen K, et al. Body

650 fluid from the parasitic worm Ascaris suum inhibits broad-acting pro-inflammatory programs in

651 dendritic cells. Immunology. 2020;159(3):322-34.

652 13. Nowarski R, Jackson R, Gagliani N, de Zoete MR, Palm NW, Bailis W, et al. Epithelial

653 IL-18 Equilibrium Controls Barrier Function in Colitis. Cell. 2015;163(6):1444-56.

654 14. Pircalabioru G, Aviello G, Kubica M, Zhdanov A, Paclet MH, Brennan L, et al.

655 Defensive Mutualism Rescues NADPH Oxidase Inactivation in Gut Infection. Cell Host

656 Microbe. 2016;19(5):651-63.

657 15. Grasberger H, Gao J, Nagao-Kitamoto H, Kitamoto S, Zhang M, Kamada N, et al.

658 Increased Expression of DUOX2 Is an Epithelial Response to Mucosal Dysbiosis Required for

659 Immune Homeostasis in Mouse Intestine. Gastroenterology. 2015;149(7):1849-59.

660 16. Huang B, Chen Z, Geng L, Wang J, Liang H, Cao Y, et al. Mucosal Profiling of

661 Pediatric-Onset Colitis and IBD Reveals Common Pathogenics and Therapeutic Pathways. Cell. 662 2019;179(5):1160-76 e24.

663 17. Keestra-Gounder AM, Byndloss MX, Seyffert N, Young BM, Chavez-Arroyo A, Tsai

664 AY, et al. NOD1 and NOD2 signalling links ER stress with inflammation. Nature.

$665 \quad 2016 ; 532(7599): 394-7$. 
Allen et al. 29

666 18. Haberman Y, Tickle TL, Dexheimer PJ, Kim MO, Tang D, Karns R, et al. Pediatric

667 Crohn disease patients exhibit specific ileal transcriptome and microbiome signature. J Clin

668 Invest. 2014;124(8):3617-33.

669 19. Mackos AR, Allen JM, Kim E, Ladaika CA, Gharaibeh RZ, Moore C, et al. Mice

670 Deficient in Epithelial or Myeloid Cell Ikappakappabeta Have Distinct Colonic Microbiomes

671 and Increased Resistance to Citrobacter rodentium Infection. Front Immunol. 2019;10:2062.

672 20. Mackos AR, Galley JD, Eubank TD, Easterling RS, Parry NM, Fox JG, et al. Social

673 stress-enhanced severity of Citrobacter rodentium-induced colitis is CCL2-dependent and

674 attenuated by probiotic Lactobacillus reuteri. Mucosal Immunol. 2016;9(2):515-26.

675 21. Galley JD, Parry NM, Ahmer BMM, Fox JG, Bailey MT. The commensal microbiota

676 exacerbate infectious colitis in stressor-exposed mice. Brain Behav Immun. 2017;60:44-50.

677 22. Zhou G, Soufan O, Ewald J, Hancock REW, Basu N, Xia J. NetworkAnalyst 3.0: a visual

678 analytics platform for comprehensive gene expression profiling and meta-analysis. Nucleic

679 Acids Res. 2019;47(W1):W234-W41.

680 23. Johansson ME. Mucus layers in inflammatory bowel disease. Inflamm Bowel Dis.

$681 \quad 2014 ; 20(11): 2124-31$.

682 24. Johansson ME, Phillipson M, Petersson J, Velcich A, Holm L, Hansson GC. The inner of

683 the two Muc2 mucin-dependent mucus layers in colon is devoid of bacteria. Proc Natl Acad Sci

684 U S A. 2008;105(39):15064-9.

685 25. Lipinski S, Till A, Sina C, Arlt A, Grasberger H, Schreiber S, et al. DUOX2-derived

686 reactive oxygen species are effectors of NOD2-mediated antibacterial responses. J Cell Sci.

687 2009;122(Pt 19):3522-30. 
688 26. Allen JM, Jaggers RM, Solden LM, Loman BR, Davies RH, Mackos AR, et al. Dietary

689 Oligosaccharides Attenuate Stress-Induced Disruptions in Immune Reactivity and Microbial B-

690 Vitamin Metabolism. Front Immunol. 2019;10:1774.

691 27. Gautam A, Kumar R, Chakraborty N, Muhie S, Hoke A, Hammamieh R, et al. Altered

692 fecal microbiota composition in all male aggressor-exposed rodent model simulating features of

693 post-traumatic stress disorder. J Neurosci Res. 2018;96(7):1311-23.

694 28. Bharwani A, Mian MF, Foster JA, Surette MG, Bienenstock J, Forsythe P. Structural \&

695 functional consequences of chronic psychosocial stress on the microbiome \& host.

696 Psychoneuroendocrinology. 2016;63:217-27.

697 29. Oshitani N, Kitano A, Okabe H, Nakamura S, Matsumoto T, Kobayashi K. Location of 698 superoxide anion generation in human colonic mucosa obtained by biopsy. Gut. 1993;34(7):9366998.

700 30. Wilkins TD, Wagner DL, Veltri BJ, Jr., Gregory EM. Factors affecting production of 701 catalase by Bacteroides. J Clin Microbiol. 1978;8(5):553-7.

702 31. Christian LM, Galley JD, Hade EM, Schoppe-Sullivan S, Kamp Dush C, Bailey MT. Gut 703 microbiome composition is associated with temperament during early childhood. Brain Behav 704 Immun. 2015;45:118-27.

705 32. Sun Y, Li L, Xie R, Wang B, Jiang K, Cao H. Stress Triggers Flare of Inflammatory 706 Bowel Disease in Children and Adults. Front Pediatr. 2019;7:432.

707 33. Johansson ME, Sjovall H, Hansson GC. The gastrointestinal mucus system in health and 708 disease. Nat Rev Gastroenterol Hepatol. 2013;10(6):352-61. 
709 34. Kulkarni DH, Gustafsson JK, Knoop KA, McDonald KG, Bidani SS, Davis JE, et al.

710 Goblet cell associated antigen passages support the induction and maintenance of oral tolerance.

711 Mucosal Immunol. 2020;13(2):271-82.

712 35. Atarashi K, Tanoue T, Ando M, Kamada N, Nagano Y, Narushima S, et al. Th17 Cell

713 Induction by Adhesion of Microbes to Intestinal Epithelial Cells. Cell. 2015;163(2):367-80.

714 36. Wang Y, Yin Y, Chen X, Zhao Y, Wu Y, Li Y, et al. Induction of Intestinal Th17 Cells

715 by Flagellins From Segmented Filamentous Bacteria. Front Immunol. 2019;10:2750.

716 37. Andresen L, Jorgensen VL, Perner A, Hansen A, Eugen-Olsen J, Rask-Madsen J.

717 Activation of nuclear factor kappaB in colonic mucosa from patients with collagenous and

718 ulcerative colitis. Gut. 2005;54(4):503-9.

719 38. Ramakrishnan SK, Zhang H, Ma X, Jung I, Schwartz AJ, Triner D, et al. Intestinal non720 canonical NFkappaB signaling shapes the local and systemic immune response. Nat Commun. $721 \quad 2019 ; 10(1): 660$.

722 39. Wrzosek L, Miquel S, Noordine ML, Bouet S, Joncquel Chevalier-Curt M, Robert V, et

723 al. Bacteroides thetaiotaomicron and Faecalibacterium prausnitzii influence the production of

724 mucus glycans and the development of goblet cells in the colonic epithelium of a gnotobiotic 725 model rodent. BMC Biol. 2013;11:61.

726 40. Png CW, Linden SK, Gilshenan KS, Zoetendal EG, McSweeney CS, Sly LI, et al.

727 Mucolytic bacteria with increased prevalence in IBD mucosa augment in vitro utilization of

728 mucin by other bacteria. Am J Gastroenterol. 2010;105(11):2420-8.

729 41. Parikh K, Antanaviciute A, Fawkner-Corbett D, Jagielowicz M, Aulicino A, Lagerholm

$730 \mathrm{C}$, et al. Colonic epithelial cell diversity in health and inflammatory bowel disease. Nature.

$731 \quad 2019 ; 567(7746): 49-55$. 
732 42. Pereira FC, Wasmund K, Cobankovic I, Jehmlich N, Herbold CW, Lee KS, et al.

733 Rational design of a microbial consortium of mucosal sugar utilizers reduces Clostridiodes

734 difficile colonization. Nat Commun. 2020;11(1):5104.

735 43. Lafuse WP, Gearinger R, Fisher S, Nealer C, Mackos AR, Bailey MT. Exposure to a

736 Social Stressor Induces Translocation of Commensal Lactobacilli to the Spleen and Priming of

737 the Innate Immune System. J Immunol. 2017;198(6):2383-93.

738 44. Rendon JL, Li X, Akhtar S, Choudhry MA. Interleukin-22 modulates gut epithelial and

739 immune barrier functions following acute alcohol exposure and burn injury. Shock.

$740 \quad 2013 ; 39(1): 11-8$.

741 45. Ratsimandresy RA, Indramohan M, Dorfleutner A, Stehlik C. The AIM2 inflammasome

742 is a central regulator of intestinal homeostasis through the IL-18/IL-22/STAT3 pathway. Cell

743 Mol Immunol. 2017;14(1):127-42.

744 46. Hammer AM, Morris NL, Cannon AR, Khan OM, Gagnon RC, Movtchan NV, et al.

745 Interleukin-22 Prevents Microbial Dysbiosis and Promotes Intestinal Barrier Regeneration

746 Following Acute Injury. Shock. 2017;48(6):657-65.

747 47. Ivanov, II, Atarashi K, Manel N, Brodie EL, Shima T, Karaoz U, et al. Induction of

748 intestinal Th17 cells by segmented filamentous bacteria. Cell. 2009;139(3):485-98.

749 48. Ibiza S, Garcia-Cassani B, Ribeiro H, Carvalho T, Almeida L, Marques R, et al. Glial-

750 cell-derived neuroregulators control type 3 innate lymphoid cells and gut defence. Nature.

$751 \quad 2016 ; 535(7612): 440-3$.

752 49. Grasberger H, El-Zaatari M, Dang DT, Merchant JL. Dual oxidases control release of

753 hydrogen peroxide by the gastric epithelium to prevent Helicobacter felis infection and

754 inflammation in mice. Gastroenterology. 2013;145(5):1045-54. 
755 50. Sommer F, Backhed F. The gut microbiota engages different signaling pathways to

756 induce Duox2 expression in the ileum and colon epithelium. Mucosal Immunol. 2015;8(2):372-

7579.

758 51. McCafferty DM. Peroxynitrite and inflammatory bowel disease. Gut. 2000;46(3):436-9.

759 52. Cross RK, Wilson KT. Nitric oxide in inflammatory bowel disease. Inflamm Bowel Dis.

$760 \quad 2003 ; 9(3): 179-89$.

761 53. Reinders CI, Herulf M, Ljung T, Hollenberg J, Weitzberg E, Lundberg JO, et al. Rectal

762 mucosal nitric oxide in differentiation of inflammatory bowel disease and irritable bowel

763 syndrome. Clin Gastroenterol Hepatol. 2005;3(8):777-83.

764 54. Fang FC. Perspectives series: host/pathogen interactions. Mechanisms of nitric oxide-

765 related antimicrobial activity. J Clin Invest. 1997;99(12):2818-25.

766 55. Kang KA, Ryu YS, Piao MJ, Shilnikova K, Kang HK, Yi JM, et al. DUOX2-mediated

767 production of reactive oxygen species induces epithelial mesenchymal transition in 5-

768 fluorouracil resistant human colon cancer cells. Redox Biol. 2018;17:224-35.

769 56. Kim SH, Lee WJ. Role of DUOX in gut inflammation: lessons from Drosophila model of

770 gut-microbiota interactions. Front Cell Infect Microbiol. 2014;3:116.

771 57. Hayes P, Dhillon S, O'Neill K, Thoeni C, Hui KY, Elkadri A, et al. Defects in NADPH

772 Oxidase Genes NOX1 and DUOX2 in Very Early Onset Inflammatory Bowel Disease. Cell Mol

773 Gastroenterol Hepatol. 2015;1(5):489-502.

774 58. Dhillon SS, Mastropaolo LA, Murchie R, Griffiths C, Thoni C, Elkadri A, et al. Higher

775 activity of the inducible nitric oxide synthase contributes to very early onset inflammatory bowel

776 disease. Clin Transl Gastroenterol. 2014;5:e46. 
59. Yoon MY, Min KB, Lee KM, Yoon Y, Kim Y, Oh YT, et al. A single gene of a

778 commensal microbe affects host susceptibility to enteric infection. Nat Commun. 2016;7:11606.

779 60. Yardeni T, Tanes CE, Bittinger K, Mattei LM, Schaefer PM, Singh LN, et al. Host

780 mitochondria influence gut microbiome diversity: A role for ROS. Sci Signal. 2019;12(588).

781 61. Ravindra Kumar S, Imlay JA. How Escherichia coli tolerates profuse hydrogen peroxide

782 formation by a catabolic pathway. J Bacteriol. 2013;195(20):4569-79.

783 62. Ormerod KL, Wood DL, Lachner N, Gellatly SL, Daly JN, Parsons JD, et al. Genomic

784 characterization of the uncultured Bacteroidales family S24-7 inhabiting the guts of

785 homeothermic animals. Microbiome. 2016;4(1):36.

786 63. Galley JD, Nelson MC, Yu Z, Dowd SE, Walter J, Kumar PS, et al. Exposure to a social 787 stressor disrupts the community structure of the colonic mucosa-associated microbiota. BMC 788 Microbiol. 2014;14:189.

789 64. Golubeva AV, Crampton S, Desbonnet L, Edge D, O'Sullivan O, Lomasney KW, et al. 790 Prenatal stress-induced alterations in major physiological systems correlate with gut microbiota 791 composition in adulthood. Psychoneuroendocrinology. 2015;60:58-74.

792 65. Love MI, Huber W, Anders S. Moderated estimation of fold change and dispersion for 793 RNA-seq data with DESeq2. Genome Biol. 2014;15(12):550.

794 66. Bokulich NA, Kaehler BD, Rideout JR, Dillon M, Bolyen E, Knight R, et al. Optimizing 795 taxonomic classification of marker-gene amplicon sequences with QIIME 2's q2-feature796 classifier plugin. Microbiome. 2018;6(1):90.

797 67. Quast C, Pruesse E, Yilmaz P, Gerken J, Schweer T, Yarza P, et al. The SILVA

798 ribosomal RNA gene database project: improved data processing and web-based tools. Nucleic

799 Acids Res. 2013;41(Database issue):D590-6. 
Allen et al. 35

800 68. Vazquez-Baeza Y, Pirrung M, Gonzalez A, Knight R. EMPeror: a tool for visualizing

801 high-throughput microbial community data. Gigascience. 2013;2(1):16.

802 69. Lozupone C, Hamady M, Knight R. UniFrac--an online tool for comparing microbial

803 community diversity in a phylogenetic context. BMC Bioinformatics. 2006;7:371.

804 70. Michel MC, Murphy TJ, Motulsky HJ. New Author Guidelines for Displaying Data and

805 Reporting Data Analysis and Statistical Methods in Experimental Biology. J Pharmacol Exp

806 Ther. 2020;372(1):136-47.

808 Figure Legends.

809 Figure 1. Stress shifts IEC transcription towards heightened inflammation, ROS production

810 and antimicrobial defenses. (a) Volcano plot based on differential expression analysis (DESeq2)

811 from RNA sequencing data reveals broad modifications to colonic IEC (EPCAM+, CD45-) gene

812 expression in response to social stress (Con vs. Str [n = 10/group]; 166 genes upregulated by Str

813 (red), 16 downregulated by Str (blue); Log Fold Change $>0.5$, Adjusted $p<10^{-5}$. (b) Differential

814 pathway analysis (NetworkAnalyst (23) of RNA sequencing data indicated Str-induced

815 upregulation in pathways (Gene ontology: Biological Pathways [GO:BP]) related to immune, ROS

816 and anti-microbial defense signaling, among others (Top ten shown; FDR p<0.05) (c) Heatmap of

817 significantly altered genes (Con [green] vs. Str [purple]) within the GO:BP Inflammatory response

818 pathway (Adjusted $\mathrm{p}<10^{-5}$ ) (d) Immunofluorescence staining confirms upregulation in protein

819 levels of the antimicrobial peptide "regenerating islet-derived protein 3-beta" (REG3 $\beta$ ), in the

820 colon of Str-exposed mice, $*=p<0.05, n=10 /$ group. Scale bar $=100 \mu \mathrm{M}$. 
822 Figure 2. Stress disrupts the colonic mucus layer. (a) Heatmap of significantly altered IEC

823 genes (Con [green] vs. Str [purple], $\mathrm{n}=10$ /group) involved in glycoprotein biosynthesis as

824 determined by RNA sequencing pathway analysis (GO:BP, DeSeq2 confirmed; $\mathrm{p}<10^{-5}$ ). (b)

825 Representative FISH staining of total bacteria (EUB-338-Cy3), lectin-based fluorescence staining

826 targeting terminal fucose sugars on mucins (UEA1- fluorescein; fucose) and host nuclei staining

827 (DAPI) within colons of Con and Str-exposed mice. (c) Colonic mucus integrity score in response

828 to $\operatorname{Str}(0=$ normal mucus thickness with bacterial adherence only on outer mucus layer, $1=$ normal

829 mucus thickness and integrity with minor bacterial penetration to inner mucus layer, $2=$ moderate

830 outer mucus layer depletion with moderate bacterial penetration to inner mucus layer, minor

831 evidence of bacterial adherence to epithelial layer, $3=$ moderate depletion of outer and inner layer

832 integrity with high bacterial penetration to inner mucus layer and moderate bacterial adherence to

833 epithelium, 4 = major mucus depletion of outer and inner layer with substantial bacterial adherence

834 to epithelium). (d) Inner mucus layer thickness (Avg thickness $(\mu \mathrm{M})$ measured over 5 crypt

835 regions). (e) Serum lipopolysaccharide-binding protein (LBP) concentrations $(\mu \mathrm{g} / \mathrm{mL})$. Scale bar

$836=100 \mu \mathrm{M}, \mathrm{n}=12 /$ group, $*=\mathrm{p}<0.05$.

838 Figure 3. Stress-induced modifications to IECs are dependent on an intact gut microbiota.

839 RT-PCR was used to analyze the expression of a select set of genes representing ROS-generating

840 (Duox2, Nos2), mucus regulating (Fut2), innate inflammatory (Saa1, Ill8) and antimicrobial

$841(\operatorname{Reg} 3 b$,$) , signaling pathways within IECs (EpCAM+ CD45-) isolated from (a) conventionally-$

842 raised (b) germ-free and (c) broad spectrum antibiotic treated C57B1/6N mice exposed to Con or

843 Str conditions. $\mathrm{n}=6-9 /$ group; $\mathrm{ns}=$ not significant at $\mathrm{p}>0.05, *=\mathrm{p}<0.05, * *=\mathrm{p}<0.01, * * *=$

$844 \mathrm{p}<0.001 . \mathrm{nd}=$ not detected. 
Allen et al. 37

846 Figure 4. IECs are primed by host stress signals to respond to immunogenic bacterial

847 components. IECs (EpCAM+, CD45-) isolated from germ-free (GF) Str-exposed and Con mice

848 ( $n=6 /$ group) were cultured ex vivo before exposure to a vehicle (VEH-phosphate-buffered saline),

849 lipopolysaccharide (E. coli LPS $[1 \mu \mathrm{g} / \mathrm{mL}]$ ) or flagellin (S. typhimurium-ultrapure FLG [200

$850 \mathrm{ng} / \mathrm{mL}]$ ) challenge for $2 \mathrm{~h}$. (a) Heatmap representing relative gene expression of GF IECs exposed

851 in vivo stress (Str) and ex vivo bacterial (LPS/FLG) challenge. Significant Str $\mathrm{x}$ LPS/FLG

852 interactions $(\mathrm{p}<0.01)$ were found for Duox 2 and Nos2. For clarity, these data are re-represented in

853 separate figures to the right of the heatmap. See Table S1 (GF) and Table S2 (CONV-R) for all

854 means \pm SEM and p-values for ex vivo experiments. (b) Representative images and quantification

855 of DUOX2 protein expression from Con and Str conventionally-raised (CONV-R) mice (n= 856 6/group). Scale bar $=100 \mu \mathrm{M} ; *=\mathrm{p}<0.05$.

Figure 5. Stress modifies gut microbiota composition concomitant to changes in host epithelium. (a) Principle coordinates analysis based on the unweighted UniFrac distance metric reveals a robust shift in colonic microbiome composition in response to Str (ADNOIS p<0.05). (b)

861 Bacterial genera significantly altered by Str exposure (top 6 altered differentially abundant genera 862 shown). (c) Spearman rho $(\rho)$ correlation coefficients relating $S 24-7$ abundance to IEC expression 863 profiles (within Str group only; top 20 out of 183 differentially expressed genes shown). (d) S248647 relative abundance positively associates with IEC Duox2 and Nos2 expression (within Str group only). $* * *=$ FDR $\mathrm{p}<0.001, * *=\operatorname{FDR} \mathrm{p}<0.01, *=\mathrm{FDR} \mathrm{p}<0.05$ 
Figure 6. Stress modifies gut microbiota catalase gene abundance and enzyme activity. (a)

868 Relative abundance of catalase gene content observed across bacterial taxa in colonic contents of

869 Con and Str mice ( $\mathrm{n}=3 /$ group). (b) Colonic luminal content catalase activity ( $\mathrm{nmol} / \mathrm{min} / \mathrm{mL})$ is

870 upregulated in Str vs. Con mice $(\mathrm{n}=5 /$ group). $*=\mathrm{p}<0.05, * *=\mathrm{p}<0.01$.

\section{Supplementary Figure Legends.}

873 Figure S1. Over enrichment (ORA) heatmap clustering analysis of IEC (EpCAM+CD45-) RNA

874 sequencing data using using the KEGG database. (a) Top 10 differentially expressed pathways.

875 (b-e) Heatmaps representing relative gene expression within selected pathways (KEGG) found to

876 be significantly different between Con [green] vs. Str [purple], FDR p<0.05 by ORA heatmap

877 clustering analysis.

879 Figure S2. ORA network analysis of IEC (CD45-, EpCAM+) RNA sequencing data. Genes entered into analysis were differentially expressed (Con vs. Str) based on the DESeq P Adj p $<0.05$.

881 Pathways in network were derived through (a) KEGG and (b) GO:BP databases and were 882 significantly different (Con vs. Str) at FDR p $<0.05$.

884 Figure S3. (a) Representative image displaying evidence of bacterial (EUB-338) penetration into mucus layer (UEA-1) and attachment to host epithelial cells (DAPI) in the colon of Str-exposed

886 mice (integrity score $=2$; arrows indicate signs of bacterial penetration into mucus layer [top arrow] and adhesion to host epithelial cells [bottom arrow]); scale bar $=20 \mu \mathrm{M}$. (b) Goblet cell number and (c) density did not differ as a result of Str. ${ }^{*}=\mathrm{p}<0.05$, ns $=$ not significant. 
Allen et al. 39

890 Figure S4. (a) Stress does not alter serum LPS-binding protein (LBP) levels in germ-free (GF)

891 animals (b) Heatmap comparing IEC (CD45-, EpCAM+) gene expression in conventionally raised

892 (CONV-R) vs GF mice. Expression data is relativized to CONV-R-Con mice. \# p<0.05 main effect

893 of GF status.

894

895 Figure S5. (a) Gene expression of toll like receptors (TLR) -4, and -5 do not differ in IECs from

896 germ-free mice as a result of Str or ex vivo bacterial (LPS or FLG) challenge. (b) Heatmap

897 representing relative gene expression of IECs from CONV-R mice exposed in vivo stress (Str) and

898 ex vivo bacterial (LPS/FLG) challenge ( $\mathrm{n}=5 /$ group). See Table $S 1$ (GF) and Table S2 (CONV-R)

899 for all means \pm SEM and p-values for ex vivo experiments.

900

901

902

903

904 
Table S1. Relative expression of select genes within IECs isolated from germ-free (GF) mice exposed to Str paradigm and stimulated ex vivo with LPS or FLG. $* \mathbf{p}<0.05, * * \mathbf{p}<0.01$.

\begin{tabular}{|c|c|c|c|c|c|c|c|c|c|c|c|}
\hline \multirow{2}{*}{ Gene } & \multicolumn{3}{|c|}{$\begin{array}{c}\text { No Stress } \\
\text { Mean Relative Expression } \\
(+/- \text { SEM })\end{array}$} & \multicolumn{3}{|c|}{$\begin{array}{c}\text { Stress } \\
\text { Mean Relative Expression } \\
(+/- \text { SEM })\end{array}$} & \multicolumn{5}{|c|}{ P-value } \\
\hline & Baseline & LPS & Flagellin & $\begin{array}{c}\text { Baselin } \\
\mathrm{e}\end{array}$ & LPS & Flagellin & $\begin{array}{l}\text { Str } \\
\text { Main } \\
\text { Effect }\end{array}$ & $\begin{array}{l}\text { LPS } \\
\text { Main } \\
\text { Effect }\end{array}$ & $\begin{array}{l}\text { FLG } \\
\text { Main } \\
\text { Effect }\end{array}$ & $\begin{array}{l}\text { Str } x \\
\text { LPS }\end{array}$ & $\begin{array}{l}\text { Str } x \\
\text { FLG }\end{array}$ \\
\hline Duox2 & $\begin{array}{c}1.03 \\
(0.04)\end{array}$ & $\begin{array}{c}2.21 \\
(0.10)\end{array}$ & $\begin{array}{c}2.18 \\
(0.06)\end{array}$ & $\begin{array}{c}1.14 \\
(0.03)\end{array}$ & $\begin{array}{c}2.76 \\
(0.13)\end{array}$ & $\begin{array}{c}3.96 \\
(0.11)\end{array}$ & $<0.01$ & $<0.01$ & $<0.01$ & 0.27 & $<0.01^{* *}$ \\
\hline Nos2 & $\begin{array}{c}1.10 \\
(0.18)\end{array}$ & $\begin{array}{c}1.65 \\
(0.18)\end{array}$ & $\begin{array}{c}1.47 \\
(0.20)\end{array}$ & $\begin{array}{c}1.20 \\
(0.27)\end{array}$ & $\begin{array}{c}2.75 \\
(0.18)\end{array}$ & $\begin{array}{c}2.10 \\
(0.29)\end{array}$ & $<0.05$ & $<0.01$ & 0.10 & $<0.01^{\star *}$ & 0.71 \\
\hline Fut2 & $\begin{array}{c}0.98 \\
(0.06)\end{array}$ & $\begin{array}{c}1.15 \\
(0.06)\end{array}$ & $\begin{array}{c}1.16 \\
(0.03)\end{array}$ & $\begin{array}{c}0.83 \\
(0.09)\end{array}$ & $\begin{array}{c}1.30 \\
(0.06)\end{array}$ & $\begin{array}{c}1.10 \\
(0.11)\end{array}$ & 0.88 & 0.07 & 0.24 & 0.37 & 0.81 \\
\hline Saa1 & $\begin{array}{c}1.01 \\
(0.03)\end{array}$ & $\begin{array}{c}1.68 \\
(0.09)\end{array}$ & $\begin{array}{c}1.36 \\
(0.06)\end{array}$ & $\begin{array}{c}0.74 \\
(0.04)\end{array}$ & $\begin{array}{c}0.92 \\
(0.09)\end{array}$ & $\begin{array}{c}0.99 \\
(0.05)\end{array}$ & 0.12 & 0.01 & $<0.01$ & 0.26 & 0.99 \\
\hline I/18 & $\begin{array}{c}1.02 \\
(0.04)\end{array}$ & $\begin{array}{c}0.95 \\
(0.03)\end{array}$ & $\begin{array}{c}0.73 \\
(0.02)\end{array}$ & $\begin{array}{c}0.86 \\
(0.07)\end{array}$ & $\begin{array}{c}0.70 \\
(0.13)\end{array}$ & $\begin{array}{c}0.68 \\
(0.21)\end{array}$ & $<0.05$ & 0.16 & 0.08 & 0.39 & 0.66 \\
\hline $\operatorname{Reg} 3 b$ & $\begin{array}{c}1.17 \\
(0.09)\end{array}$ & $\begin{array}{c}1.14 \\
(0.03)\end{array}$ & $\begin{array}{c}1.00 \\
(0.03)\end{array}$ & $\begin{array}{c}0.85 \\
(0.06)\end{array}$ & $\begin{array}{c}1.15 \\
(0.06)\end{array}$ & $\begin{array}{c}1.27 \\
(0.09)\end{array}$ & 0.94 & 0.41 & 0.51 & 0.31 & 0.13 \\
\hline
\end{tabular}


Table S2. Relative expression of select genes within IECs isolated from conventionally raised (CONV-R) mice exposed to Str paradigm and stimulated $e x$ vivo with LPS or FLG. *p<0.05, **p<0.01.

\begin{tabular}{|c|c|c|c|c|c|c|c|c|c|c|c|}
\hline \multirow{2}{*}{ Gene } & \multicolumn{3}{|c|}{$\begin{array}{c}\text { No Stress } \\
\text { Mean Relative Expression } \\
(+/- \text { SEM })\end{array}$} & \multicolumn{3}{|c|}{$\begin{array}{c}\text { Stress } \\
\text { Mean Relative Expression } \\
(+/- \text { SEM })\end{array}$} & \multicolumn{5}{|c|}{ P-value } \\
\hline & Baseline & LPS & Flagellin & $\begin{array}{l}\text { Baseli } \\
\text { ne }\end{array}$ & LPS & Flagellin & $\begin{array}{c}\text { Str } \\
\text { Main } \\
\text { Effect }\end{array}$ & $\begin{array}{l}\text { LPS } \\
\text { Main } \\
\text { Effect }\end{array}$ & $\begin{array}{l}\text { FLG } \\
\text { Main } \\
\text { Effect }\end{array}$ & $\begin{array}{l}\text { Str } x \\
\text { LPS }\end{array}$ & $\begin{array}{l}\text { Str x } \\
\text { FLG }\end{array}$ \\
\hline Duox2 & $\begin{array}{c}1.09 \\
(0.16)\end{array}$ & $\begin{array}{c}1.38 \\
(0.15)\end{array}$ & $\begin{array}{c}1.44 \\
(0.25)\end{array}$ & $\begin{array}{c}1.80 \\
(0.18)\end{array}$ & $\begin{array}{c}2.03 \\
(0.35)\end{array}$ & $\begin{array}{c}2.30 \\
(0.28)\end{array}$ & $<0.01^{* *}$ & 0.20 & $<0.05^{*}$ & 0.85 & 0.39 \\
\hline Nos2 & $\begin{array}{c}1.27 \\
(0.18)\end{array}$ & $\begin{array}{c}2.30 \\
(0.31)\end{array}$ & $\begin{array}{c}2.24 \\
(0.29)\end{array}$ & $\begin{array}{c}2.37 \\
(0.61)\end{array}$ & $\begin{array}{c}4.07 \\
(0.46)\end{array}$ & $\begin{array}{c}3.64 \\
(0.77)\end{array}$ & $<0.01^{* *}$ & $<0.01^{* *}$ & 0.06 & 0.71 & 0.66 \\
\hline Fut2 & $\begin{array}{c}1.02 \\
(0.09)\end{array}$ & $\begin{array}{c}1.01 \\
(0.05)\end{array}$ & $\begin{array}{c}1.16 \\
(0.09)\end{array}$ & $\begin{array}{c}1.38 \\
(0.17)\end{array}$ & $\begin{array}{c}1.76 \\
(0.40)\end{array}$ & $\begin{array}{c}1.28 \\
(0.34)\end{array}$ & $<0.01^{* *}$ & 0.37 & 0.70 & 0.41 & 0.72 \\
\hline Saa1 & $\begin{array}{c}1.28 \\
(0.29)\end{array}$ & $\begin{array}{c}1.09 \\
(0.27)\end{array}$ & $\begin{array}{c}1.28 \\
(0.19)\end{array}$ & $\begin{array}{c}1.58 \\
(0.30)\end{array}$ & $\begin{array}{c}1.89 \\
(0.46)\end{array}$ & $\begin{array}{c}1.82 \\
(0.25)\end{array}$ & $<0.05^{\star}$ & 0.79 & 0.80 & 0.55 & 0.76 \\
\hline I/18 & $\begin{array}{c}1.02 \\
(0.05)\end{array}$ & $\begin{array}{c}1.00 \\
(0.14)\end{array}$ & $\begin{array}{c}0.92 \\
(0.10)\end{array}$ & $\begin{array}{c}0.87 \\
(0.03)\end{array}$ & $\begin{array}{c}1.02 \\
(0.09)\end{array}$ & $\begin{array}{c}0.82 \\
(0.05)\end{array}$ & 0.28 & 0.30 & 0.60 & 0.56 & 0.73 \\
\hline$R e g 3 b$ & $\begin{array}{c}1.22 \\
(0.57)\end{array}$ & $\begin{array}{c}1.81 \\
(0.82)\end{array}$ & $\begin{array}{c}3.17 \\
(1.09)\end{array}$ & $\begin{array}{c}3.50 \\
(1.18)\end{array}$ & $\begin{array}{c}3.84 \\
(0.70)\end{array}$ & $\begin{array}{c}2.41 \\
(0.70)\end{array}$ & $<0.05^{\star}$ & 0.59 & 0.52 & 0.86 & 0.47 \\
\hline
\end{tabular}


Allen et al. 42

Table S3. List of reagents and chemicals 


\begin{tabular}{|c|c|c|}
\hline REAGENT OR RESOURCE & SOURCE & IDENTIFIER \\
\hline \multicolumn{3}{|l|}{ Antibodies } \\
\hline Sheep anti-mouse REG3 $\beta-1: 250$ & R\&D Systems & Cat \#: AF5110; \\
\hline DUOX pan serum- 1:1000 & $\begin{array}{l}\text { Dr. Xavier } \\
\text { Dedeken's lab }\end{array}$ & N/A \\
\hline CD45 MicroBeads- Mouse & Miltenyi Biotec & Cat \#: 130-052-031 \\
\hline CD326 (EpCAM) MicroBeads-Mouse & Miltenyi Biotec & Cat \#: 130-105-958 \\
\hline $\begin{array}{l}\text { Secondary antibodies-conjugated to } \\
\text { AlexaFluor dyes }-1: 500\end{array}$ & $\begin{array}{l}\text { Thermo Fisher } \\
\text { Scientific }\end{array}$ & N/A \\
\hline $\begin{array}{l}\text { Ulex-Europeaus Agglutinin I- } \\
\text { Fluorescein }\end{array}$ & $\begin{array}{l}\text { Vector } \\
\text { Laboratories }\end{array}$ & Cat \#: FL-1061 \\
\hline \multicolumn{3}{|l|}{ FISH Probes } \\
\hline EUB338-Cy3 & $\begin{array}{l}\text { Integrated DNA } \\
\text { Technologies }\end{array}$ & Сy3/GCTGCCTCCCGTAGGAGT/Сy3 \\
\hline \multicolumn{3}{|l|}{ Commercial Assays } \\
\hline Catalase Activity Assay & Abcam & Cat \#: ab83464 \\
\hline PureLink RNA mini kit & ThermoFisher & Cat \#: 1218035 \\
\hline LBP Mouse ELISA Kit & Hycult & Cat \#: HK205-02 \\
\hline \multicolumn{3}{|l|}{ Antibiotic Cocktail } \\
\hline Kanamycin sulfate & Sigma-Aldrich & Cat \#: 60615 \\
\hline Ampicillin & Sigma-Aldrich & Cat \#: 10835242001 \\
\hline Metronidazole & Sigma-Aldrich & Cat \#: M1547 \\
\hline Vancomycin Hydrochloride & Sigma-Aldrich & Cat \#: 1709007 \\
\hline Mouse PCR primers & & Sequence- 5'-3' \\
\hline $\operatorname{Reg} 3 b$ & $\begin{array}{l}\text { Integrated DNA } \\
\text { Technologies }\end{array}$ & $\begin{array}{l}\text { Fw-GTTTCAGATACCACAGACCTGG } \\
\text { Rv- TTGAGCACAGATACGAGGTGT }\end{array}$ \\
\hline $\operatorname{Reg} 3 g$ & $\begin{array}{l}\text { Integrated DNA } \\
\text { Technologies }\end{array}$ & $\begin{array}{l}\text { Fw- AAAGCAGTGGTAACAGTGG } \\
\text { Rv- CACCTCTGTTGGGTTCATAG }\end{array}$ \\
\hline 1118 & $\begin{array}{l}\text { Integrated DNA } \\
\text { Technologies }\end{array}$ & $\begin{array}{l}\text { Fw- CCTGAAGAAAATGGAGACCTGG } \\
\text { Rv- TCATATCCTCGAACACAGGCT }\end{array}$ \\
\hline Duox2 & $\begin{array}{l}\text { Integrated DNA } \\
\text { Technologies }\end{array}$ & $\begin{array}{l}\text { Fw- ACCCTGGACCTCTATTCAG } \\
\text { Rv-ACAGCCCATTCCTAGTGT }\end{array}$ \\
\hline $\operatorname{Nos} 2$ & $\begin{array}{l}\text { Integrated DNA } \\
\text { Technologies }\end{array}$ & $\begin{array}{l}\text { Fw- AGTGAAAAGTCGAGCCGCA } \\
\text { Rv-ACAATCCACAACTCGCTCCA }\end{array}$ \\
\hline
\end{tabular}


Allen et al. 44

\begin{tabular}{|l|l|l|}
\hline Saal & $\begin{array}{l}\text { Integrated DNA } \\
\text { Technologies }\end{array}$ & Fw- TTCCAAGGGGCTGGGGA \\
& Rv-GTCTGAGTTTTCCAGTTAGCTTCC \\
\hline $\boldsymbol{F u t 2}$ & $\begin{array}{l}\text { Integrated DNA } \\
\text { Technologies }\end{array}$ & Fw- TCCACCATCATCCACCTCCA \\
& Rv-AGGACATTTGAACCGCCTGTAA \\
\hline $\boldsymbol{E E F 2}$ & $\begin{array}{l}\text { Integrated DNA } \\
\text { Technologies }\end{array}$ & $\begin{array}{l}\text { Fw- TGTCAGTCATCGCCCATGTG } \\
\text { Rv- GGAGATGGCGGTGGATTTGA }\end{array}$ \\
\hline
\end{tabular}




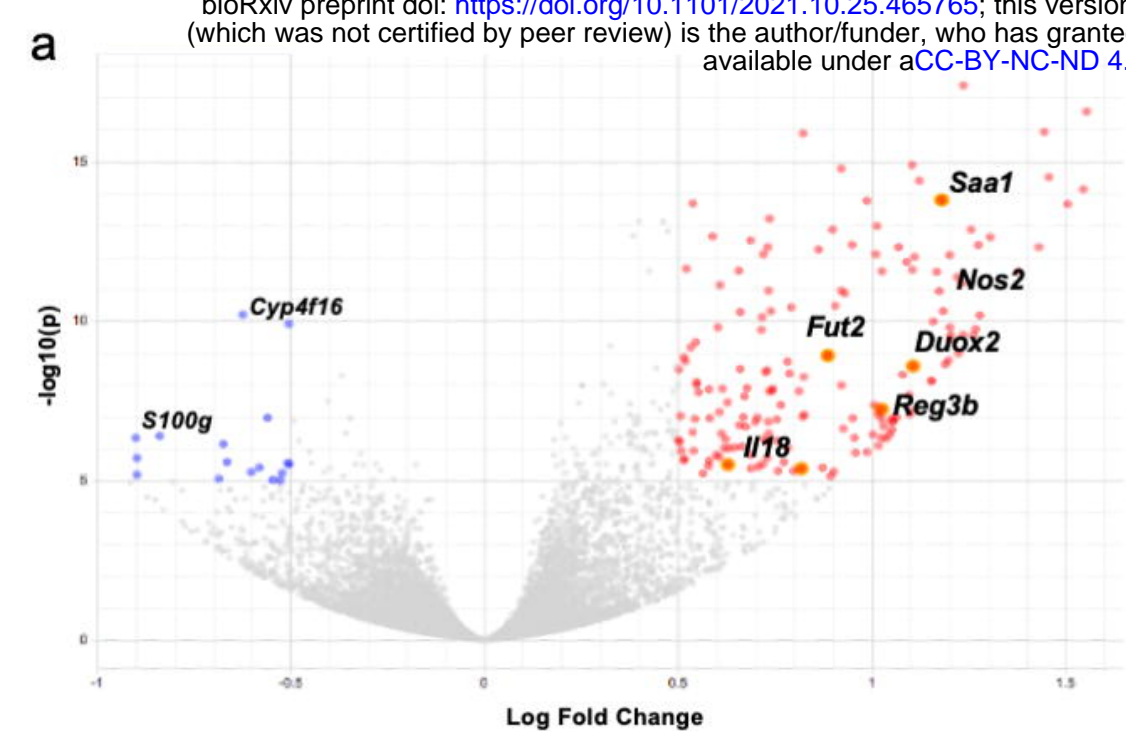

C

\section{GO: BP-Inflammatory response}

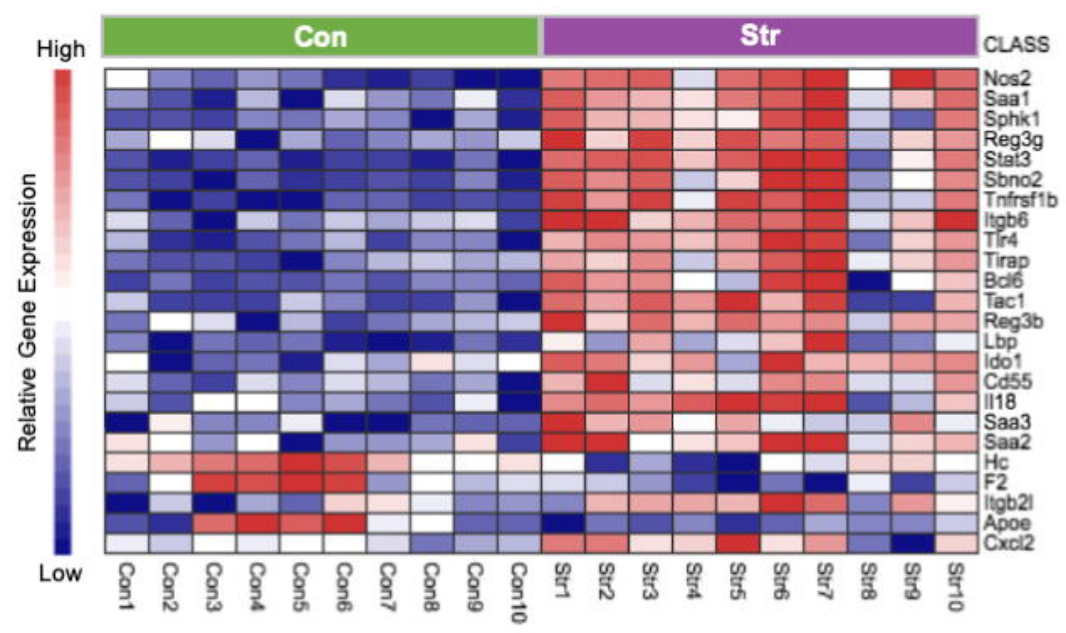

GO: Biological Pathways

Inflammatory response-

Defense response to bacterium-

Positive regulation of lymphocyte activation-

Response to wounding-

Superoxide metabolic process-

Cellular nitrogen compound catabolic process-

Small GTPase mediated signal transduction-

Defense response-

I_kappaB kinase/NF_kappaB cascade-

Glycoprotein biosynthetic process-

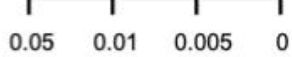

FDR p-value

d
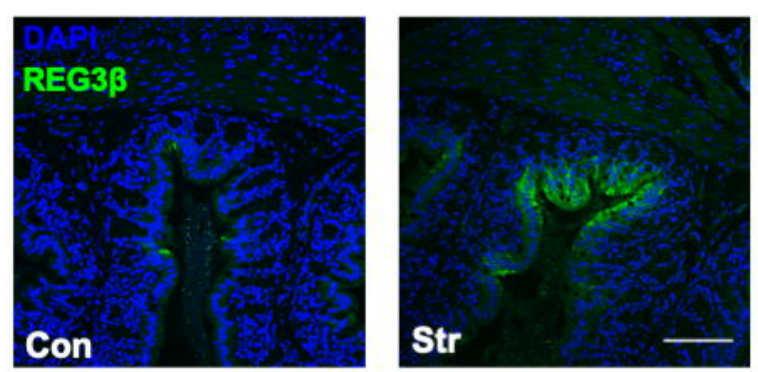

REG3 $\beta$

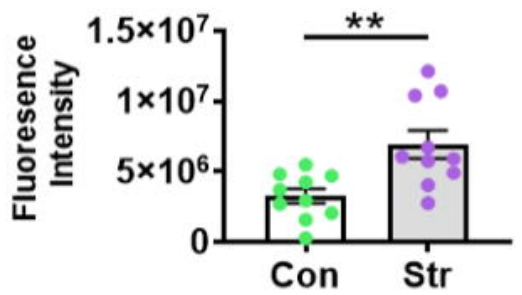


bioRxiv preprint doi: https://doi.org/10.1101/2021.10.25.465765; this version posted October 26, 2021. The copyright holder for this preprint (which was not certified by peer review) is the author/funder, who has granted bioRxiv a license to display the preprint in perpetuity. It is made available under aCC-BY-NC-ND 4.0 International license.

a

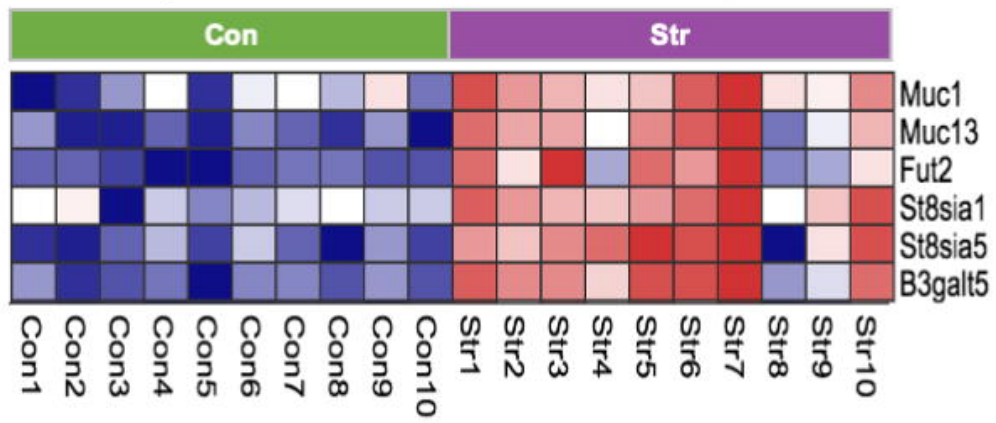

Low

C

Mucus Disruption Score

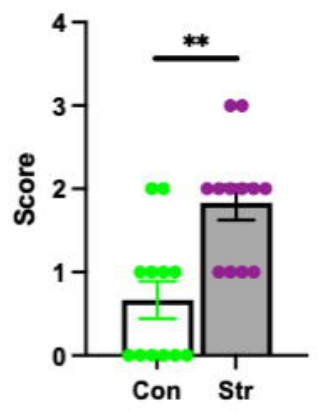

d

High

Relative Gene Expression
Mucus Thickness

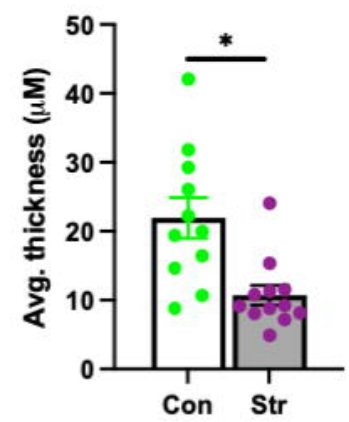

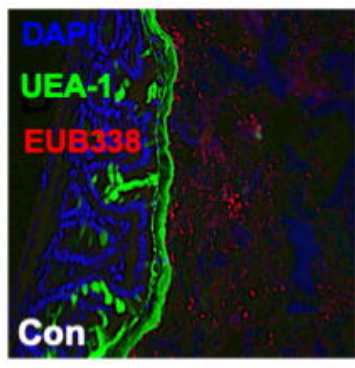

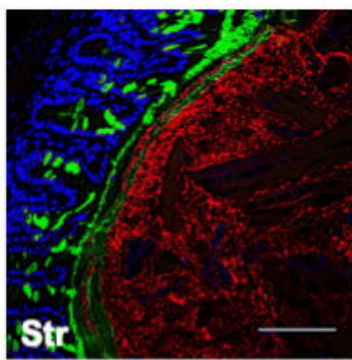

e

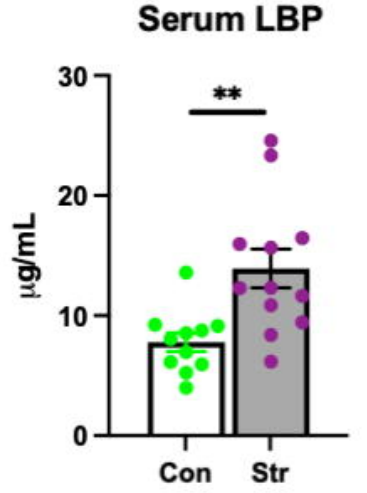


bioRxiv preprint dol: https://doi.org/10.1101/2021.10.25.465765; this version posted October 26, 2021. The copyright holder for this preprint

(which was not certified by peer review) is the author/funder, who has granted bioRxiv a license to display the preprint in perpetuity. It is made

a

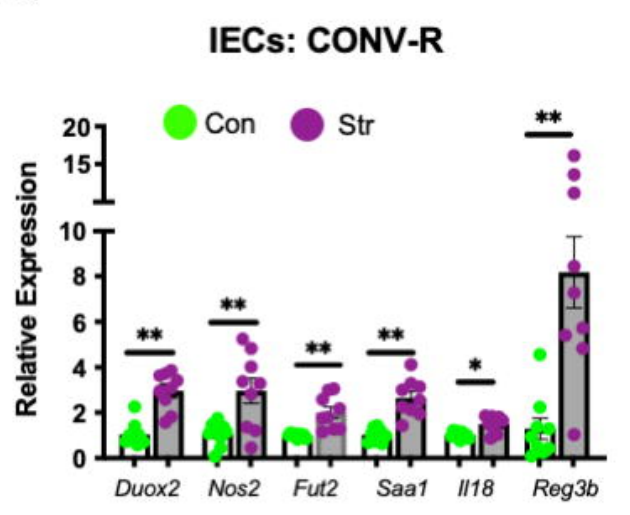

available under aCC-BY-NC-ND 4.0 International license.

b

IECs: GF

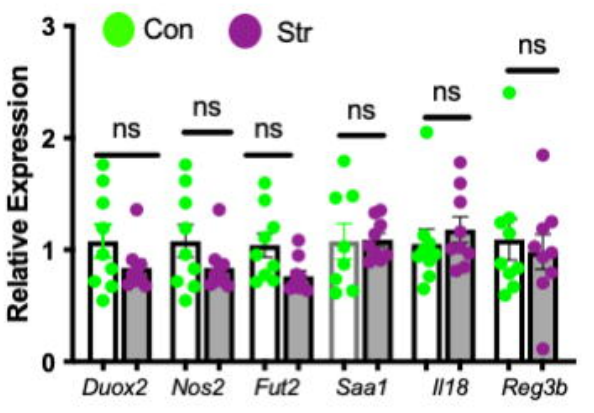

C

INCs: ABX

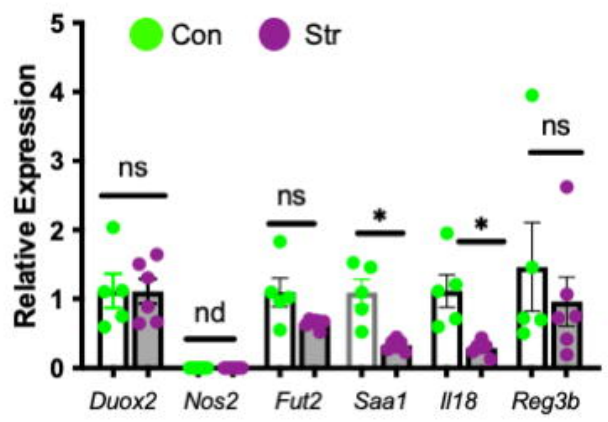


a

\section{GF: IECS}

SAL

LPS

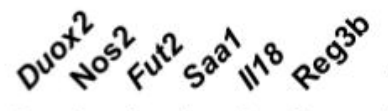

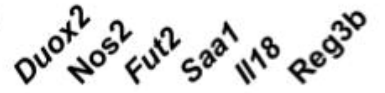

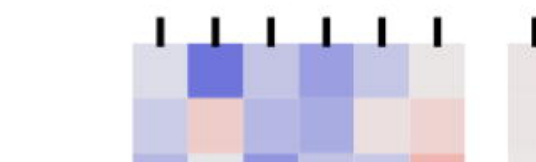

FLG

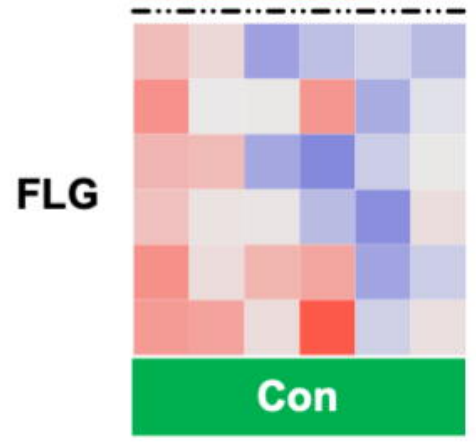

I I I I I I
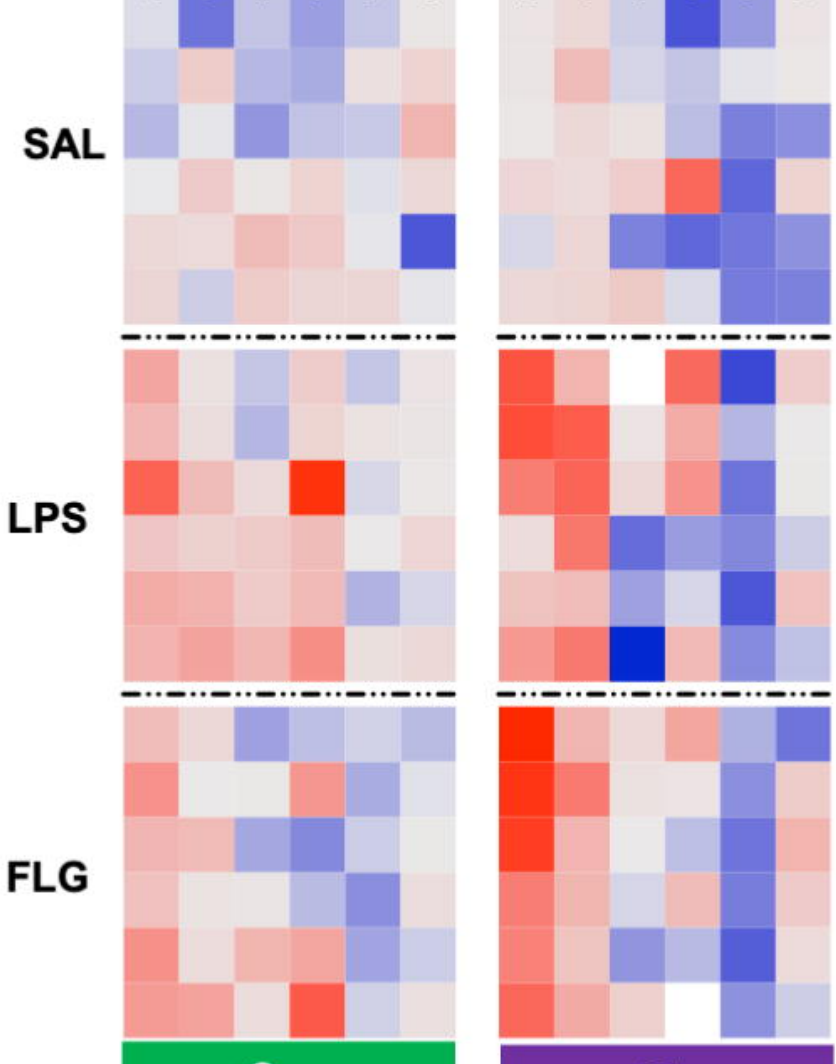

\section{Str}

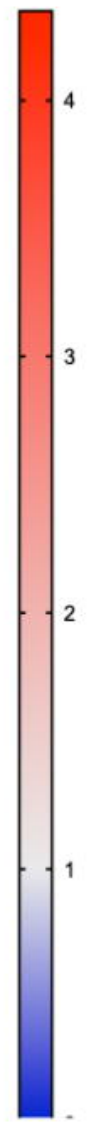

CONV-R: Colon

b
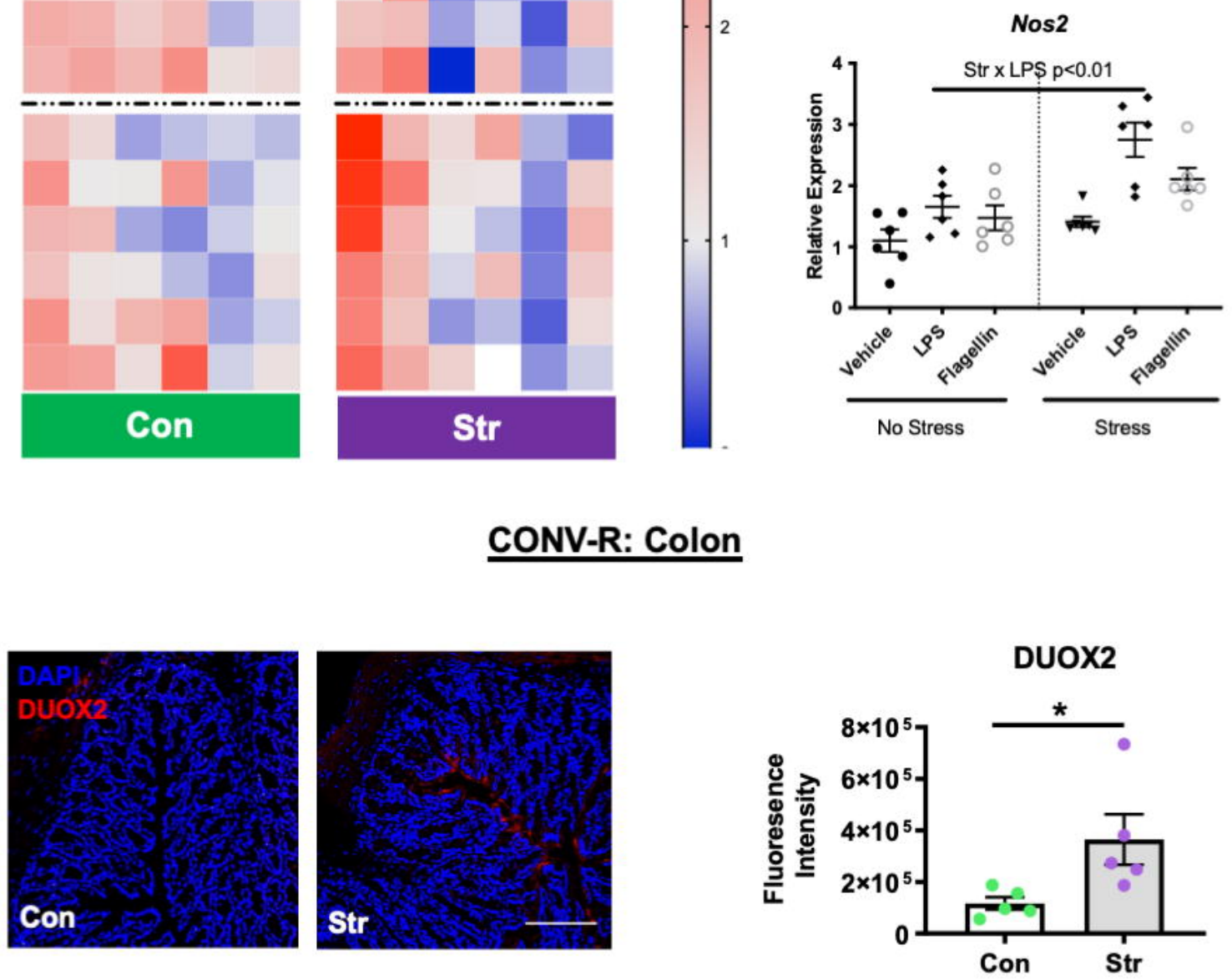


\section{\begin{tabular}{|l} 
Con \\
Str
\end{tabular}}

C

Spearman $\rho$

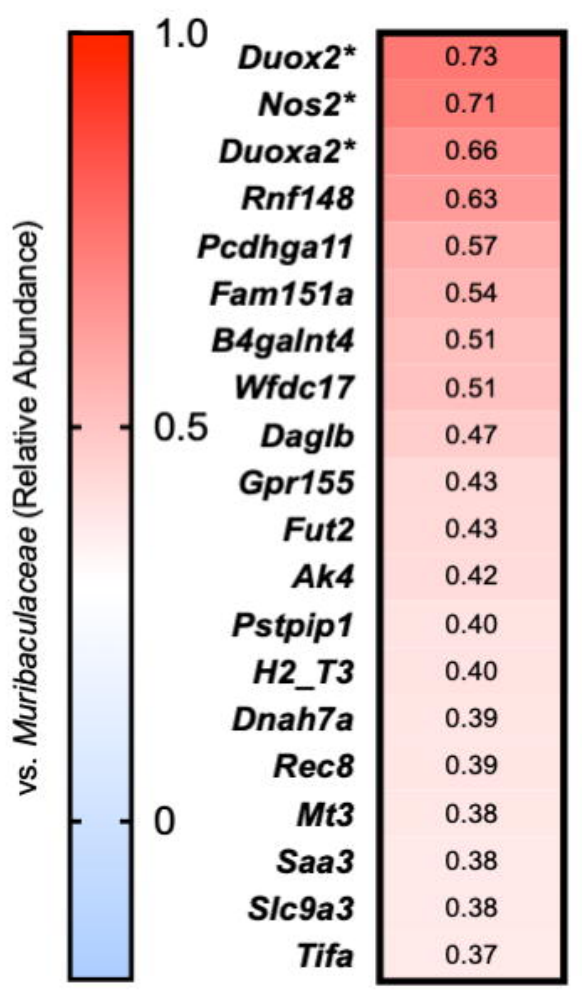

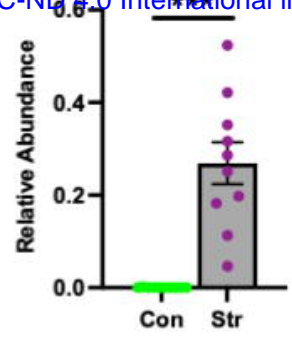

Candidatus_Arthromitus

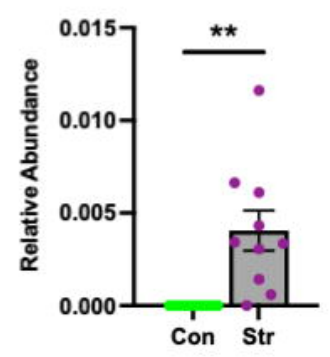

Marvinbryantia

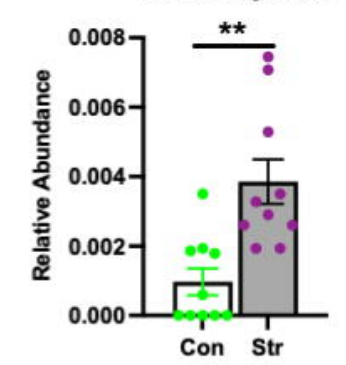

d

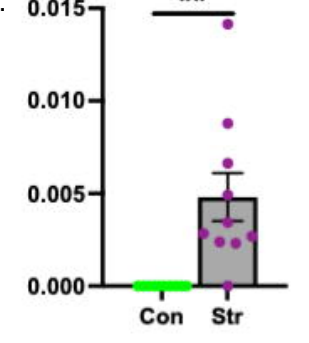

Lachnospiraceae_uncultured

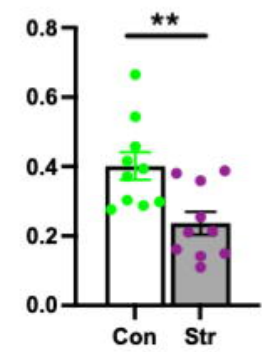

Lachnospiraceae NK4A136

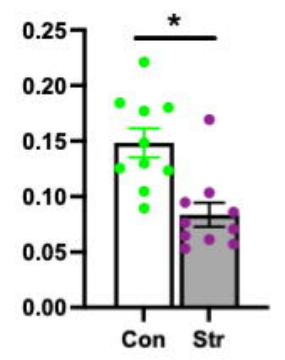

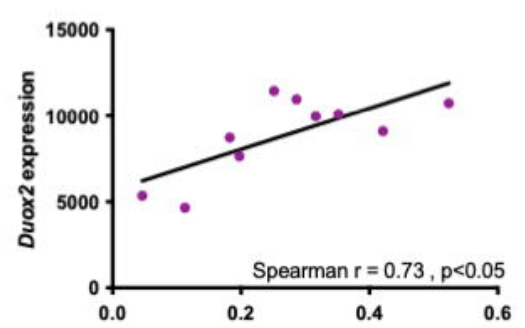

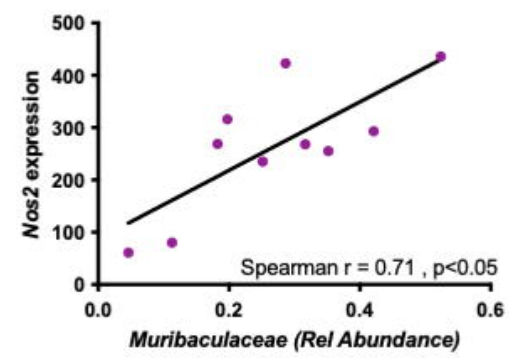


bioRxiv preprint doi: https://doi.org/10.1101/2021.10.25.465765; this version posted October 26, 2021. The copyright holder for this preprint (which was not certified by peer review) is the author/funder, who has granted bioRxiv a license to display the preprint in perpetuity. It is made

a

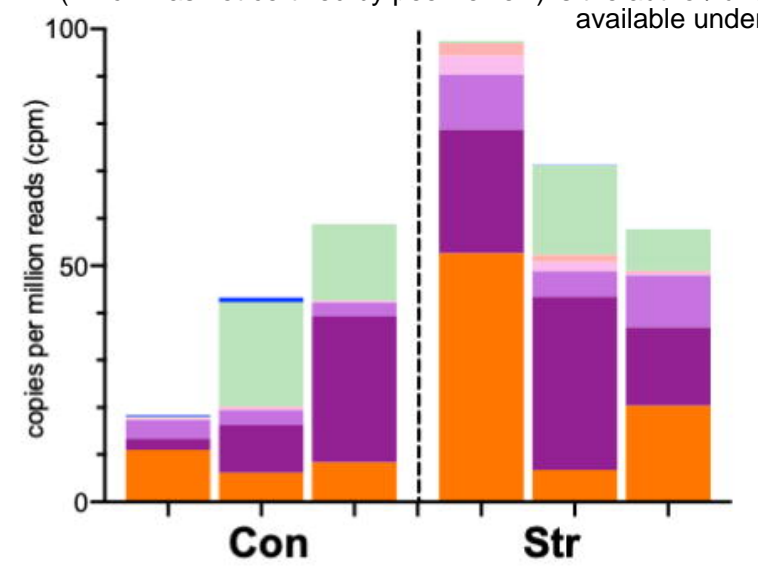

Catalase Activity

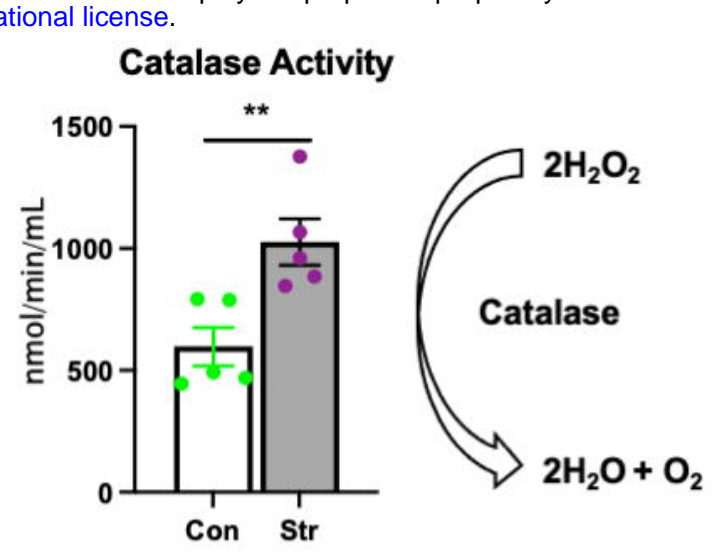

\footnotetext{
- Catalaselg__Parabacteroides.s__Parabacteroides_goldsteinii

- Catalaselg__Bacteroides.s_Bacteroides_intestinalis

- Catalaselg_Bacteroides.s_Bacteroides_thetaiotaomicron

- Catalaselg_Bacteroides.s_Bacteroides_salyersiae

- Mn-containing catalase $\mid$ ___Bacteroides.s_Bacteroides_thetaiotaomicron

- Catalaselg__Mucispirillum.s_Mucispirillum_schaedleri

- Catalaselg__Akkermansia.s__Akkermansia_muciniphila

- Catalaselg_Enterococcus.s_Enterococcus_faecalis
} 